\title{
Charcoal as an Alternative Reductant in Ferroalloy Production: A Review
}

\author{
Gerrit Ralf Surup ${ }^{1, *}$, Anna Trubetskaya ${ }^{2}\left(\mathbb{D}\right.$ and Merete Tangstad ${ }^{1}$ (1) \\ 1 Department of Materials Science and Engineering, Norwegian University of Science and Technology, \\ 7491 Trondheim, Norway; merete.tangstad@ntnu.no \\ 2 Department of Chemical Sciences, University of Limerick, V94 T9PX Castletroy, Ireland; \\ anna.trubetskaya@ul.ie \\ * Correspondence: gerrit.r.surup@ntnu.no; Tel.: +47-934-73-184
}

Received: 12 October 2020; Accepted: 3 November 2020; Published: 9 November 2020

check for updates

\begin{abstract}
This paper provides a fundamental and critical review of biomass application as renewable reductant in integrated ferroalloy reduction process. The basis for the review is based on the current process and product quality requirement that bio-based reductants must fulfill. The characteristics of different feedstocks and suitable pre-treatment and post-treatment technologies for their upgrading are evaluated. The existing literature concerning biomass application in ferroalloy industries is reviewed to fill out the research gaps related to charcoal properties provided by current production technologies and the integration of renewable reductants in the existing industrial infrastructure. This review also provides insights and recommendations to the unresolved challenges related to the charcoal process economics. Several possibilities to integrate the production of bio-based reductants with bio-refineries to lower the cost and increase the total efficiency are given. A comparison of challenges related to energy efficient charcoal production and formation of emissions in classical kiln technologies are discussed to underline the potential of bio-based reductant usage in ferroalloy reduction process.
\end{abstract}

Keywords: charcoal; pyrolysis; bio-based reductant; ferroalloy industry; kiln

\section{Introduction}

Charcoal is one of the first man-made products which has been used for millennia. First application of charcoal were found from about 30,000 to 35,000 BC [1], and its first usage in metallurgy can be dated to about $6000 \mathrm{BC}$ for copper production [2] respectively to about $1800 \mathrm{BC}$ initiating the Iron Age [3]. Charcoal enabled high energy intense processes, such as glass production and metal smelting [4] and was used as the major energy source in industrial processes until the industrial revolution, when is was replaced by coal and its derivatives. Nowadays, charcoal is used as a fuel for heating and barbecue, and is considered as a reductant for ferrosilicon processes in Norway and Brazil [5]. However, metallurgical production continues to rely on fossil-based reductants due to limited knowledge of charcoal properties and high costs.

The global production of charcoal increased from 40.5 million tonnes in 2002 [6] to 53.2 million tons in 2018 [7], in which about two third were produced in Africa. Fuelwood and charcoal generate between 2 to $7 \%$ of global greenhouse gas (GHG) emissions, mainly caused by deforestation, and combustion-related pollutants [7]. Brazil is the largest producer of charcoal with an annual average production of 6.5 million tons between 1993-2017 [8,9]. It was reported that about 50\% of charcoal were produced from planted Eucalyptus wood [10]. Over the last decades, charcoal production shifted from primary to secondary forestry, reducing anthropogenic $\mathrm{CO}_{2}$ emissions by deforestation $[8,11]$. Large amounts of Brazil's charcoal are used in the metallurgical industry that 
consumes about 10 million tons of charcoal per year and replaces fossil fuels for pig-iron (30\%), steel $(15 \%)$ and ferroalloy (98\%) production [8]. In Europe, the production of charcoal from wood has almost vanished in the last centuries [12], leading to the charcoal import from countries like Brazil, Nigeria or Tunisia.

The metallurgical industry in one of the most energy intensive industrial sectors. About 10\% of the annual anthropogenic $\mathrm{CO}_{2}$ emissions are ascribable the direct and indirect GHG emissions from metallurgical industry [13-15]. These emissions are mainly produced by carbothermal reduction processes, such as blast furnaces (BF), electric arc furnaces (EAF) and submerged arc furnaces (SAF), and by power production. About 1 billion tons of metallurgical coal are consumed in global steel industry [14]. About half of it was used to produce 350 million tons of coke used in metallurgical processes [16]. The consumption of raw materials is highly dependent on the final product and used furnace type. For example, the consumption of reducing agents increases from 500-550 kg per metric ton high carbon ferrochrome ( $\mathrm{HC} \mathrm{FeCr}$ ) in closed furnaces to $550-700 \mathrm{~kg}$ per metric ton in open furnaces, whereas only $410-500 \mathrm{~kg}$ per metric ton of high carbon ferromanganese (HC FeMn) are required in closed furnaces [17].

On average, special materials and high quality steels are composed of about $3 \%$ ferroalloys [17]. The ferroalloy industry refers to iron alloys with a high portion of additional elements, such as aluminium, chromium, manganese or silicon. Ferroalloys were initially produced in small-scale blast furnaces in the second half of the 19th century [17]. The scale of production increased with the introduction of electric arc furnaces, in which the major production nowadays takes place. The electrical consumption is in the range of 3000 to $3500 \mathrm{kWh}$ per metric ton of ferroalloy, respectively up to 7000 to $8000 \mathrm{kWh}$ per metric ton of high-silicon ferroalloy [17]. The electrical resistance of the charge material is used to heat the hearth of the electric furnace, in which a higher resistivity enables a deeper electrode tip position in the furnace [18]. Simulation have shown that a lower electrode tip positions can decrease current through the burden by about one third [19], improving the temperature profile inside the smelter.

Bio-based reductants have potential to replace the reductants made from fossil-based materials in metallurgy [20,21]. Between 800 and $1200 \mathrm{~kg}$ of wet woodchips and about $10 \%$ charcoal have been used for the silicon production in the EU countries [22,23]. The current demand of sustainable carbon for ferroalloy production is smaller than the production of charcoal, whereas the markets and quality of charcoal are very diverse. The production and usage of charcoal can have a socioeconomic impact on different regions and should be considered beside the technical requirements for metallurgical application. The Food and Agriculture Organization of the United Nations summarized the main sustainable development goals for charcoal to poverty reduction, food security and nutrition, health and availability of clean water, sustainable energy and sustainable forest management to ensure the conservation of biodiversity [7]. Some kilns used for the charcoal production do not include off-gas cleaning systems and Thus, can release unburned by-products to the environment. These emissions are composed of particulate matter (PM), volatile organic compounds (VOC) and combustion products. Volatile pyrolysis products can be reduced by at least $80 \%$ by using an afterburner [24], in which the $\mathrm{CO}_{2}$ emissions from the process are increased. Modern technologies produce charcoal continuously or semi-continuously, in which the off-gases are combusted or recirculated to provide the energy for the pyrolysis process $[1,25]$. However, only limited improvements have been made for these technologies over the last decades. Thus, charcoal production should be based on a sustainable forestry with concomitant reduction in $\mathrm{CO}_{2}$ emissions.

Norway has a significant potential of forest-based resources due to the high ratio of hydro-power in their energy supply and the availability of unexploited forests [26]. Biocarbon in combination with carbon capture and storage (CCS) is intended to reduce the $\mathrm{CO}_{2}$ emissions from Norwegian metallurgical industry by 6.8 million tons $\mathrm{CO}_{2}$-equivalence per year in $2050[27,28]$. To substitute the fossil fuel carbon reductants in the ferroalloy industry, biocarbon reductants with specific chemical, mechanical, and electrical properties are required $[18,23]$. In this review, current technologies and 
the resulting properties of charcoal are discussed to understand (i) how bio-based reductants can replace fossil fuel-based carbon and (ii) how charcoal production routes can be improved to enable an economical production in Europe.

\section{The Process Chain of Renewable Reductants}

The properties of carbon reductants are crucial for a stable operation of SAF [16,18]. Differences in chemical and physical properties compared to fossil fuel based reductants could lead to a range of technical challenges for the bioreductant use in ferroalloy production. Currently used fossil fuel reductants generally provide a high mechanical stability and low gas reactivity. The fixed carbon content of fossil fuel reductants is expected to be larger than $85 \%$, whereas ash content should be less than $12 \%$. Ash constituents such as alkali and alkali earth metals, phosphorous and sulfur should be low to minimize catalytic reactions and slag formation. The high volatile matter content of biomass and it derivatives can be problematic for especially closed hearth SAF. Selected properties of biomass, charcoal and fossil fuel coke are summarized in Table 1, while minimum requirements for metallurgical processes are summarized in chapter 4 (Table 5). The typical particle size of carbon reductants in SAF can vary from 5 to $30 \mathrm{~mm}[29,30]$. It is obvious that raw biomass must be processed to fulfill the required properties in SAF. While wood has been used as the only feedstock over the millennia, herbaceous biomass waste [31-34] and algae [35] can be also considered as feedstocks nowadays. Possible steps for the charcoal production and use as a reductant in ferroalloy industries are shown in Figure 1.

Table 1. Comparison of biomass and charcoal properties to fossil fuel reductants used in ferroalloy production [36-39].

\begin{tabular}{cccccc}
\hline Property & Unit & Wood & Herbaceous Biomass & Industrial Charcoal & Coke \\
\hline Fixed carbon & $\%$ & $15-20$ & $15-20$ & $65-85$ & $86-88$ \\
Ash content & $\%$ & $0.1-1.0$ & $1-12$ & $0.4-4$ & $10-12$ \\
Compressive strength & $\mathrm{kg} \mathrm{cm}^{-2}$ & $250-400$ & - & $10-80$ & $130-160$ \\
Bulk density & $\mathrm{kg} \mathrm{m}^{-3}$ & $100-850 *$ & $80-310$ & $180-350$ & $500-550$ \\
Electrical resistance & $\Omega \mathrm{m}$ & Very high & Very high & High & Low \\
$\mathrm{CO}_{2}$ reactivity & - & High & High & Medium-high & Low-medium \\
\hline
\end{tabular}

* 100-310 for wood chips and 300-850 for stemwood.

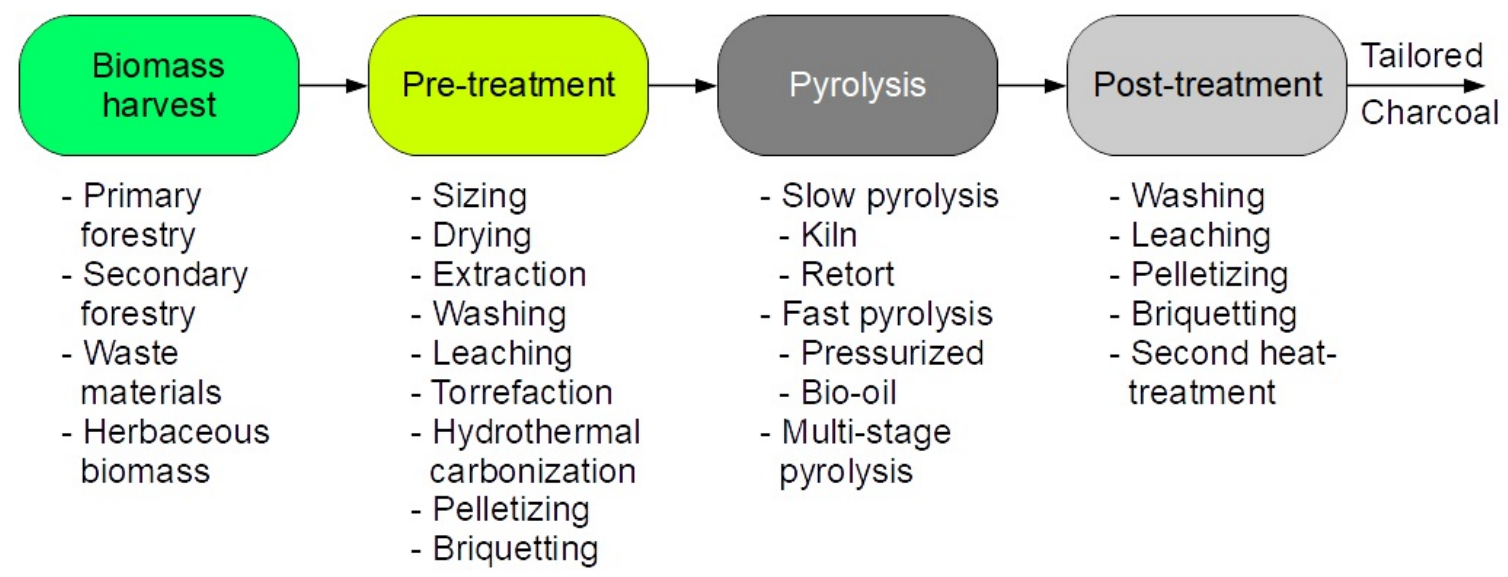

Figure 1. Schematic of the possible charcoal production steps. 
Charcoal is defined as a solid residue from wood pyrolysis. Pyrolysis is the thermochemical decomposition of organic material at elevated temperatures, most often between 350 to $700{ }^{\circ} \mathrm{C}$, in absence of oxygen. The required thermal energy is provided by the partial combustion of additional feedstock or pyrolysis by-products, i.e., gas and oil (volatile matter), which is released during pyrolysis. While charcoal kilns have been used over millenia and are still used in several countries, modern kilns and large-scale retorts are the main production processes in industrialized countries.

\subsection{Biomass Composition}

The most common biomass used as a renewable reductant is wood. However, due to the high price of woody biomass, alternative feedstock such as herbaceous biomass or waste have become more attractive in recent years. Biomass is a mixture of organic compounds and mineral matter. Woody biomass is mainly composed of cellulose, hemicellulose, lignin and minor amounts of extractives, in which softwood has a greater lignin content than hardwood, whereas the cellulose, hemicellulose and extractives are greater in hardwood [40]. The compositional analysis of herbaceous biomass as well as selected softwood and hardwood species is shown in Table 2. The analysis of specific feedstock can be found elsewhere [38,41], such as differences between bark and stemwood [42].

The biomass constituents have a major impact on the product properties, composition and yields in thermochemical conversion. The constituents react in broad temperature ranges using different mechanisms, pathways and rates [43] and Thus, affect the primary and secondary reactions in the kiln or retort. Pyrolysis reactions of cellulose are mainly endothermic, whereas decomposition of lignin and secondary decomposition of volatiles are exothermic $[43,44]$. Thus, biomass composition has a strong effect on the char yield and by-product composition.

The volatile composition is based on the biomass feedstock and heating rate of the process, in which cellulose, hemicellulose and lignin (CHL) decompose to characteristic monomer and monomer-related fragments [45]. Cellulose decomposes in the temperature range between 280 to $380^{\circ} \mathrm{C}$ with a maximum reaction rate at $350^{\circ} \mathrm{C}[46,47]$. Hemicellulose decomposes in the wider temperature range between 190 to $380^{\circ} \mathrm{C}$ with a maximum reaction rate at 260 and $310^{\circ} \mathrm{C}$ [48-51]. Lignin decomposes in the widest temperature range between 200 to $500^{\circ} \mathrm{C}$ with a maximum reaction rate at 360 and $400^{\circ} \mathrm{C}[48,50,52]$. Thus, thermal breakdown (degradation) of hemicellulose is larger than that cellulose and larger than that of lignin [43]. The pyrolysis of cellulose results in a formation of levoglucosan and its derivatives [46] with a solid residue of 7-20\% [53]. The char yield from xylan can be twice greater than that of cellulose and three times greater than that of glucomannan [54,55]. Lignin has the greatest solid yield with about $50 \%$ at $500{ }^{\circ} \mathrm{C}$, further decreasing to $40 \%$ at $900{ }^{\circ} \mathrm{C}[55,56]$.

Minerals in the ash can catalyze primary and secondary pyrolysis reactions. Potassium and silica showed a greater catalytic effect on the remaining radical concentration compared to the CHL composition in the biomass [57]. In addition, charcoal forming reactions under fast heating rates were much stronger affected by the potassium content than by CHL composition [58]. Sugar and sugar derivatives were increased at the cost of carbonyls and phenolic compounds after acid leaching [59]. To evaluate the conversion performance of biomass, five grades on basis of the compositional and proximate analyses were established [60]. 
Table 2. Composition of hardwood, softwood, wheat straw and rice husks.

\begin{tabular}{|c|c|c|c|c|c|c|}
\hline & Cellulose & Hemicellulose & $\begin{array}{l}\text { Lignin } \\
/ \mathrm{wt} . \%\end{array}$ & Extractives & Ash & Sources \\
\hline \multicolumn{7}{|c|}{ Herbaceous biomass } \\
\hline Wheat straw & 37.4 & 25.5 & 16.00 & 6.2 & 8.6 & [38] \\
\hline Rice husks & 33.7 & 22.0 & 22.8 & 9.8 & 11.0 & [38] \\
\hline Bagasse & 38.0 & 27.5 & 18.5 & 10.6 & 10.9 & [38] \\
\hline \multicolumn{7}{|c|}{ Softwood } \\
\hline Softwood & 43.1 & 27.7 & 29.2 & & 0.5 & [43] \\
\hline Stem wood & 43 * & $28 *$ & $29 *$ & & & {$[61]$} \\
\hline Pinewood & $38.3-40.7$ & $17.8-26.9$ & $27.0-31.4$ & $5.0-8.8$ & 0.3 & {$[42,62]$} \\
\hline Spruce & $37.8-42.0$ & $25-27.3$ & $27.4-28.6$ & $2.0-7.8$ & 0.8 & {$[42,63]$} \\
\hline \multicolumn{7}{|c|}{ Hardwood } \\
\hline Hardwood & 43.0 & 35.3 & 21.7 & & 0.4 & [43] \\
\hline Stem wood & $43 *$ & $35 *$ & $22 *$ & & & [61] \\
\hline Eucalyptus & $46.1-48.8$ & $21.9-22.5$ & $28.8-31.4$ & $3.1-5.0$ & $0.1-0.2$ & [64] \\
\hline Beechwood & 35.0 & 19.2 & 33.5 & 7.5 & 1.4 & {$[62]$} \\
\hline Birch & 43.9 & 28.9 & 20.2 & 3.8 & & [42] \\
\hline Oak & 36.7 & 18.7 & 21.9 & 11 & 1.6 & [63] \\
\hline \multicolumn{7}{|c|}{ Birch } \\
\hline Stem wood & 43.9 & 28.9 & 20.2 & 3.8 & & [42] \\
\hline Bark & 10.7 & 11.2 & 14.7 & 25.6 & & [42] \\
\hline Branches & 33.3 & 23.4 & 20.8 & 13.5 & & [42] \\
\hline
\end{tabular}

* On dry ash free basis.

\subsection{Pre-Treatment of Raw Feedstock and Charcoal}

Ferroalloy industries require pre-treatment processes to have a low capital and operating cost and also to be effective on a wide range and loading of lignocellulosic material. To improve biomass properties for transport, storage and thermochemical conversion, biomass can be pretreated by resizing and drying. Fresh woody biomass provides a moisture content up to $60 \%$ [65] and $\approx 80 \%$ for fresh algae $[66,67]$. To reduce the energy demand in the first pyrolysis stage, biomass should be naturally dried to less than $25 \%$ [68]. The equilibrium moisture content of wood can vary from 4 to $18.1 \mathrm{wt} . \%$ [69], similar to that of dried herbaceous biomass such as wheat straw or rice husks. A high moisture content increases the energy demand for pyrolysis, resulting in a decreased energy conversion efficiency [70]. In addition, the amount of bio-oil would be increased by a larger water fraction, but with a decreased amount of organic compounds and heating value [71,72].

A stem wood length of 5 to $6 \mathrm{~m}$ is most often used for road transport in Europe. The feedstock size must be adjusted to the thermochemical conversion process, whereas a length of $\approx 30 \mathrm{~cm}$ and a thickness of 10-18 cm are required for pyrolysis retorts, respectively a length of $60-120 \mathrm{~cm}$ and a diameter of $12-20 \mathrm{~mm}$ for charcoal kilns [25,73], or milled to fines for fast pyrolysis processes [74]. Sawdust from sawmills is therefore useful for fast and flash pyrolysis units, or must be densified by pelletizing or briquetting. Herbaceous biomass must be milled and densified to be usable in classical charcoal production. However, fine biomass milling is energy-consuming, and fibrous particles with low bulk densities may cause feeding problems.

The use of a bioreductant that is more reactive in $\mathrm{CO}_{2}$ than fossil-based coke may increase maintenance costs of the metallurgical process [75,76]. Ash constituents such as potassium act as a catalyst for $\mathrm{CO}_{2}$ reactivity and should be minimized. Stem wood can be debarked to reduce the ash content of the feed material and increase the value of the woody biomass [77], in which debarking can be carried out with modified harvesting heads in the forests [78]. The removal of bark from wood logs reduces the concentration of alkali metals which can have a negative impact on the metal parts of the kiln leading to corrosion. One of the major challenges of agricultural residues is therefore related to its 
quality, such as a higher ash content of problematic alkali metal compounds. Washing or leaching are common methods to reduce the ash content of the parental feedstock.

Thermochemical processes such as torrefaction and hydrothermal carbonization can be used to improve physicochemical properties. However, and efficient and cost-effective biomass pre-treatment is very important for overcoming biomass limitations and hurdles in use of biocarbon-based reductants in the ferroalloy industry. Value-added compounds may be removed from the biomass prior to the pyrolysis process to improve the economics of the process chain. In contrast to classical charcoal production require extraction processes wood particles of small size for the high process efficiency. Thus, particle size of the material must be adjusted for each step in a process chain, and should target a final particle size that can vary from 5 to $30 \mathrm{~mm}$ for the further use as a reductant in ferroalloy industries $[29,30]$. Briquetting or pelletizing can be carried out after the extraction process.

\subsection{Milling/Grinding}

The particle size of the feedstock material must be adjusted for each step in the process chain, and should target a final particle size between 5 to $30 \mathrm{~mm}$ for the further use as renewable reductant $[29,30]$. While wood is sawed and split into logs prior to charcoal production, herbaceous biomass must be milled and grinded prior to its compaction. The pre-treatment of herbaceous biomass can be adopted from biomass combustion, where the lignocellulosic materials are first decentralized milled and pelletized, and second biomass pellets are then milled using coal roller mills prior to combustion [79]. A number of studies [80-88] have investigated the influence of mill type on both the particle size and shape. Momeni [80] showed that comminuting woody pellets in hammer and roller mills produced significantly different sized particles. In other investigations [81,83], higher fractions of fine particles were obtained after comminution in a hammer mill compared to milling using a knife mill. In agreement with this observation, the energy consumption of the knife mill was found in all cases to be smaller than that of the hammer mill [82,83]. The feedstock type (hardwood, straw, corn cobs and corn stover) affected the energy consumption of the hammer and disk mills [84].

The energy consumption for the comminution of dry pellets was lower for the hammer mill than for the disk mill, and the particle size distribution was broader with larger particle aspect ratios after comminution in the hammer mill [86]. In addition, it was reported that a high moisture content ( $>20 \%$ ) increased the specific energy consumption by $50 \%$ [86]. It appeared that different feedstocks (switchgrass, corn and soybean) showed differences in the particle size and shape during comminution and generated particles with various morphological properties $[87,88]$. Milling of the thermally treated material showed that the energy efficiency can increase twice at temperatures up to $180^{\circ} \mathrm{C}$ and decrease at carbonization temperatures above $270{ }^{\circ} \mathrm{C}$ reduced by factor of 4 [89].

Particles should be milled to an optimal size for the consecutive processes, in which a later densification must be ensured. Biomass can be compacted by pelletization and briquetting, in which pellets showed best mechanical stability for a broad particle size distribution and a low amount $(\leq 20 \%)$ of particles less than $0.5 \mathrm{~mm}$ [90]. However, pellets produced from smaller particle sizes $(\leq 300 \mu \mathrm{m})$ resulted in a higher yield stress and density than for larger particles $(300-600 \mu \mathrm{m})$ [91]. Particles larger $5 \mathrm{~mm}$ can be compacted by briquetting.

\subsection{Washing/Leaching}

The alkali metals, particularly potassium, calcium and sodium catalyze the thermal degradation of biomass, increasing the yield of reaction water and decreasing the yield of tar and char [92,93]. Other soluble inorganic species can also be problematic because of their effects on the charcoal properties, such as increased reactivity, electrical conductivity and purity of base metals [94,95]. Water leaching removes alkali sulfates, carbonates, and chlorides, whereas $\mathrm{HCl}$ leaches carbonates and sulfates of alkaline earth and other metals [96]. For example, ash content of wheat straw and rice husks were reduced by nearly $50 \%$ by acid leaching [97-99], in which especially alkali and alkali-earth metals were removed. In addition, ammonia removes organic compounds of $\mathrm{Mg}, \mathrm{Ca}, \mathrm{K}$ and $\mathrm{Na}$. Overall, 
leaching with dilute acids is known to remove only soluble metals which are not physiologically bound to the matrix of lignocellulosic feedstocks, while dilute alkali or other catalysts are required to disrupt cell walls and release ash components which are physiologically bound to the feedstock matrix [33]. However, previous studies have shown that leaching of biomass can also remove the organic fraction, especially reducing the lignin amount [92,100].

Leaching can also result in a loss of cellulose and hemicelluloses through hydrolysis pre-treatment [101]. Another challenge related to the biomass leaching with the acid catalysts is the remaining acid in the charcoal matrix that requires post-processing including calcination or disposal of catalysts and additional washing of charcoal with the deionized water. Concurrently, water washing may also be desirable to reduce volatilization of sulfur and chlorine products during pyrolysis [102,103]. In addition, leaching may increase the energy density up to $25 \%$ through increased heating values and pellet density [104]. Differences in carbon structure suggest that leaching of original biomass affect the charcoal properties after heat treatment at elevated temperatures, whereas temperature is the dominant process variable at temperatures above $2000^{\circ} \mathrm{C}[62,105]$. The alkali and alkali-earth metals are removed in a rapid phase, whereas other elements are removed in slow phases which can exceed several days [106]. Boiling-water leaching is inferior to acid leaching to remove ash elements, but superior on the basis of investment costs and chemical demand [98]. However, the removal of these elements is beneficial for the metallurgical industry [105], since these are catalyzing the Boudouard reaction.

\subsection{Extraction}

The separation of extractives (e.g., lipids/resin acids) from the biomass feedstock provides a possibility to considerably reduce off-gassing and provides valuable chemicals or biofuel for the energy sector and metallurgical industries [107]. The extracted fatty/resin acids can be utilized as primary feedstocks for chemicals and biorefinery applications [108-111], whereas the wood fraction after extraction is of high importance as a source of green carbon that could be utilized in metallurgical industries. Several methods exist for the extraction of high-value molecules from biomass including conventional organic solvent extraction, hydrodistillation, low-pressure solvent extraction and hydrothermal feedstock processing [112-114].

Supercritical fluids demonstrate properties between those of a liquid and a gas, with the viscosity of a supercritical fluid being an order of magnitude lower than a liquid, whereas the diffusivity is an order of magnitude higher and Thus, leading to the enhanced heat and mass transfer [115]. The properties of a solvent can be fine-tuned by varying the temperature and pressure. Conventional solvents traditionally utilized in wax extraction (such as hexane) are frequently viewed as being problematic due to the toxicological and environmental impacts [116]. Supercritical fluid extraction using $\mathrm{CO}_{2}$ as a solvent has an easily accessible critical point, is non-flammable, has minimal toxicity and is widely available [117]. Supercritical $\mathrm{CO}_{2}$ extraction $\left(\mathrm{scCO}_{2}\right)$ has been conducted on a commercial scale for over two decades for the extraction of high-value products from biomass [118]. Supercritical extraction process has been shown to improve the off-gassing of wood pellets, thus reducing the potential for uncontrolled auto-oxidation, while maintaining pellet properties $[107,119]$. Moreover, supercritical $\mathrm{CO}_{2}$ extraction can also improve the physicochemical properties of solid char from pyrolysis at high temperatures, leading to greater electric conductivity and low reactivity of charcoal [120]. Supercritical $\mathrm{CO}_{2}$ extraction increases the bending strength and stiffness of residual wood and, Thus, decreases the cost of process scaling up, wood storage and transportation [121].

The pre-treatment using $\mathrm{scCO}_{2}$ extraction of wood removes more than half of value-added compounds without any significant influence on the physical properties of original wood and on the yield of solid charcoal [122]. Under properly selected treatment conditions (e.g., $>1100{ }^{\circ} \mathrm{C}$ ), charcoal samples can be produced from a mixture of different low quality wood fractions with reactivity and dielectric properties approaching that of fossil-based metallurgical coke and with the low content of liquid products, including naphthalene, PAHs, aromatic and phenolic fractions. 


\subsection{Torrefaction}

Torrefaction is a mild pyrolysis process that converts biomass into a carbon material with increased energy density and decreased oxygen content, removing smoke-forming volatiles and result in a product yield of $\approx 45-70 \%$ of the initial weight [123,124]. Torrefaction contributes to dehydration, deoxygenation, partial degassing, and structural changes through breaking hemicellulose, lignin and cellulose chains at elevated temperatures [125], in which the lignin content is increased by $\approx 10-15 \%$ [124]. This leads to increased calorific value that improves biomass physiochemical properties during co-firing with coal $[126,127]$. For example, the feedstock becomes more uniform that improves pelletization and the flow properties of torrefied products [123] and the energy density is increased to more than $20 \mathrm{GJ} \mathrm{m}^{-3}$ [124].

The higher heating value of torrefied olive stones $\left(28.8 \mathrm{MJ} \mathrm{kg}^{-1}\right)$ at $300{ }^{\circ} \mathrm{C}$ can be achieved in a rotary slow pyrolysis reactor to meet the requirements of metallurgical industries [128]. In addition, the torrefaction length did not have a strong influence on the $\mathrm{CO}_{2}$ reactivity of olive stones, whereas the temperature and particle size had a significant influence on the composition and product yields [129]. Longer torrefaction times and greater heat treatment temperatures led to the improvement of higher heating value of olive stones leading to higher carbon and lower oxygen content. One way to improve torrefied biomass handling and combustion properties is by densification into briquettes or pellets which have many advantages over torrefied feedstock including reduction of dust, improved handling properties and higher bulk density (up to $66 \%$ greater) [130].

\subsection{Hydrothermal Carbonization}

In hydrothermal carbonization (HTC) feedstocks remains in contact with hot, compressed water increasing carbon and hydrogen contents and also producing hydrochar with a high stability [131]. HTC treatment generates three products: gases, liquid compounds, and hydrochar that contains $80-95 \%$ of the energy content of the raw feedstock and 55-90\% of the original mass [132]. Gaseous products cover $\approx 10 \%$ by mass of the raw feedstock and liquid compounds, primarily hydroxymethylfurfural, furfural, phenol, pentoses, hexoses, comprise the remainder of the products [133]. HTC is carried out in a hot liquid water in the temperature range 180 to $250{ }^{\circ} \mathrm{C}$ at solids loading ranging from 7 to $25 \%$, and reaction time ranging from a few minutes to several hours [134]. Specifically, HTC removes a significant fraction of undesired inorganic elements such as $\mathrm{Na}$ and $\mathrm{K}$ that would otherwise contribute to slag [135]. Previous studies showed that the alkali content can be further reduced by increasing the heat treatment temperature or by washing the hydrochar with the deionized water after the pre-treatment [136]. In addition, hydrochar has superior mechanical properties and pelletability compared with torrefaction or pyrolysis biochar [129,137]. Besides the complexity of structure-property relationship, the use of bioreductants is hindered by the price of feedstock and hydrochar yield $[138,139]$. Thus, a limited number of studies using lignocellulosic biomass and waste has been conducted to investigate the hydrochar properties for the use in ferroalloy industries.

\subsection{Pelletizing and Briquetting}

Densification processes such as pelletizing and briquetting can significantly reduce carbon losses due to dust formation. In addition, pelletizing and briquetting provide the product with a defined uniform shape and size [133]. Combined carbonization and pelletizing can be used to increase the fuel value of feedstock by increasing its energy density and improving its handling and transport processes in the reduction furnace [140]. One of the challenges in using renewable reductants in metallurgical processes is related to its fragility with the generation of large amounts of fine particles during transportation and storage [141]. The mechanical strength of biomass pellets can be improved through pelletization or briquetting and is slightly larger than that of charcoal pellets [142]. However, recent studies have shown that pelletizing charcoal fines increase the usable carbon yield in ferroalloy production [143]. 
In ferroalloy industries, manganese ore pellets must be sintered at higher temperatures to provide a mechanical stability that is similar to that of iron ore pellets. The addition of wood dust and dolomite are known to increase the required sintering temperature of the ore pellets and Thus, generally used in iron and manganese alloy production $[16,144]$. The use of pellets from charcoal-ore blends is known to reduce the electricity demand and increase the yield of elemental manganese [145]. Current metallurgical production is based on the use of fossil-based fuels because the use of biomass-ore and charcoal-ore pellets in the reduction process can increase the overall power consumption by 72-152 kWh per tonne of FeMn and will increase the cost of the reduction process [146].

Previous studies showed that the durability of high quality pellets is required to be $>97.5 \%$ to fulfill the criteria of the European Standard Committee CET/TC 335 and be used in ferroalloy production [147]. Pelletizing of HTC char prepared at $200-240{ }^{\circ} \mathrm{C}$ provided mechanically stable bioreductants compared to the dried torrefied-based pellets without an additional binder [135,148,149]. An additional heat treatment improved the agglomeration of the hydrochar particles, increasing the durability of hydrochar pellets to $>95 \%$ at temperatures above $300{ }^{\circ} \mathrm{C}$ [129]. A maximum durability of $98.5 \%$ was measured during the heat treatment of hydrochar at $450{ }^{\circ} \mathrm{C}$ showing similar properties to charcoal pellets with the pre-mixed bio-oil binder $[63,150]$. Torrefied biomass particles are loose and nonuniform due to decreased hemicellulose content [126]. In comparison, mechanical strength and pelletability of torrefied charcoal are less compared to that of HTC chars [135,137,151]. Therefore, the pre-treatment of biomass under the HTC conditions might be more suitable for the production of reductants for the ferroalloy industries than torrefaction.

\subsection{Slow Pyrolysis}

Slow pyrolysis is the thermal decomposition of organic feedstocks i.e., biomass, coal in an inert atmosphere at low heating rates (up to $20^{\circ} \mathrm{C} \cdot \mathrm{min}^{-1}$ ). Slow pyrolysis processes are used to produce solid products like biochar or charcoal from biomass $[152,153]$. The feedstock is firstly dried by driving off the moisture and pore water of the organic feedstock. The dried feedstock undergoes a thermal decomposition of the organic matrix with increasing temperature, in which volatile compounds are released. The product composition is based on the feedstock and process conditions, such as heating rate, heat treatment temperature and residence time. Biomass is heated up to about 300 to $700^{\circ} \mathrm{C}$, and up to $50 \mathrm{wt} . \%$ of the feedstock are recovered as solid residue [56,154]. Pyrolysis at temperatures less than $1200^{\circ} \mathrm{C}$ is defined as carbonization process [40], in which the solid yield decreases with increasing heat treatment temperature. The volatile fraction is composed of condensates (e.g., bio-oil) and pyrolysis gases, such as $\mathrm{CO}, \mathrm{CO}_{2}, \mathrm{H}_{2}$ and $\mathrm{CH}_{4}$. The solid pyrolysis product is rich in carbon [155], whereas the liquid by-products from biomass pyrolysis have a high oxygen content. The final yield and quality of the pyrolysis products are affected by the feedstock composition, pre-treatment, heat treatment temperature, heating rate, reaction gas atmosphere, particle residence time, pressure and catalysts (e.g., alkali and alkali earth metals) $[152,154,156]$.

In general, the pyrolysis of biomass follows a three-step mechanism as described above: 1. dehydration, 2. primary pyrolysis reactions and 3. secondary pyrolysis reactions. Primary pyrolysis reactions include dehydrogenation, depolymerization, and fragmentation reactions of the organic matrix, and can be considered as homogenous reactions. Secondary (and ternary) pyrolysis reactions summarize the reactions of intermediate decomposition products and gas reactions, as well as the heterogeneous reactions with the formed char [56]. Moreover, secondary reactions of bio-oil compounds can increase the solid yield by more than 4\%-points [63]. Previous studies have shown that secondary reactions can be induced by long residence times, large particles and increased pressure $[157,158]$, and are affected by the ash yield and composition.

Charcoal yields are maximized at low heating rates, long residence times and high pressures [157,158], where increased pressure leads to an increase in a char yield (up to 50\%) with the decreased residence time [159]. Classical charcoal is produced at a temperature below $700^{\circ} \mathrm{C}$ at low heating rates. An operation cycle can vary from 7 days to more than 30 days $[160,161]$ and is accounted as slow 
pyrolysis. At temperatures of $400-450{ }^{\circ} \mathrm{C}$, about $37-50 \%$ charcoal, $34-47 \%$ bio-oil (4-11\% tar, 30-36\% aqueous phase), and 14-29\% permanent gases are formed from wood [8,10,162]. However, due to the partial combustion of feedstock and undefined process conditions in kilns, charcoal yield is highly influenced by the skills of the operator, and is generally less than $20-25 \%$ on dry basis $[160,163,164]$. Industrial retorts used in Europe provide a charcoal yield of $\approx 35 \%$ on dry basis [153]. Char yields of 15-43 wt.\% can be obtained for the slow pyrolysis of microalgae [35], similar as reported for agricultural residues [25,32].

Recent studies have shown that multi-stage pyrolysis processes can improve the solid yield and reduce its energy demand. The fixed carbon yield can be increased by $11 \%$ to $25.7 \%$ by a three-stage pyrolysis process with different heating rates, resulting in an energy saving of 20-30\% $[165,166]$. This approach incorporates the temperature regions of endothermic and exothermic reactions and Thus, enables a better control of product yield and quality. However, the multi-stage pyrolysis requires carefully design to obtain the optimized product yield and energy savings [167] and no multi-stage process was installed on industrial scale when this review was initiated.

\subsection{Fast Pyrolysis}

Fast and flash pyrolysis of biomass are mainly used to produce liquid biofuels (e.g., bio-oil) at high heating rates $\left(>100^{\circ} \mathrm{C} \mathrm{s}^{-1}\right)$ and reduced to atmospheric pressure. At a heat treatment temperature of $500{ }^{\circ} \mathrm{C}$, about $24 \mathrm{wt} . \%$ of solid residue (including ash) can be recovered [168], whereas high yields of charcoal are formed at increased pressure [152,157]. The greater charcoal yield and the larger throughput in pressurized pyrolysis can improve the economics of the overall process, in which the fixed carbon yield can be increased to $70-85 \%$ of the theoretical value [157]. However, the fixed carbon content of the produced charcoal was less than 85\% [152,157] and Thus, increases the demand for enhanced off-gas cleaning systems due to the reduced quality of the off-gases $[169,170]$ or additional post-treatment.

Properties of flash pyrolysis char and soot differ from that of industrial charcoal and may be considered as an alternative resource in metallurgy. The solid residue is strongly affected by the feedstock composition and final temperature in the process [171]. Charcoal from fast pyrolysis exhibits a higher volatile matter content compared to slow pyrolysis char produced at same temperature [172]. The charcoal yield of wood and herbaceous biomass decreases to less than $4 \%$ on dry ash free basis at temperatures above $1000{ }^{\circ} \mathrm{C}[173,174]$, whereas the formation of soot increases at temperatures larger than $900^{\circ} \mathrm{C}$ with a maximum yield between 1100 to $1250{ }^{\circ} \mathrm{C}[97,175]$. Biomass with a high lignin content will form larger soot yields compared to biomass which is enriched in cellulose or xylan content [171,176], in which the soot and tar formation is reduced by high concentrations of alkali metals. At temperatures larger than $1000^{\circ} \mathrm{C}$, beechwood and straw samples retained their original structure, while low ash pinewood underwent a morphological transformation with a highly molten surface [100]. Cellulose pyrolysis under high heating rates produces mostly permanent gases and a limited amount of bio-oil [171].

Fast pyrolysis processes are technically complex [177] and will require a profound understanding of the primary and secondary pyrolysis reactions [164] to provide a biocarbon with the required properties for metallurgical application. A major drawback of bio-oil from fast pyrolysis is the lack of integrated biorefinery concepts into metallurgy [178]. The bio-oil is generally upgraded into a valuable biofuel or chemical feedstock [179]. In addition, bio-oil can be used in the ferroalloy industry as a binder for carbon briquettes, pellets and agglomerates $[63,150,180]$ or as feedstock for electrode material [181]. The large fractions of small aromatics (e.g., benzene and toluene) and phenols which are found mostly in lignin bio-oil are beneficial for the use as a binder [176]. However, both process chains would require an additional post-treatment of the collected bio-oil samples. 


\subsection{Emissions}

The charcoal fuel cycle from classical charcoal production is one of the most GHG intensive energy sources used by mankind [5]. Liquid and gaseous products from biomass pyrolysis can be accounted as value-added by-products or emissions. Charcoal is commonly produced in simple kiln technologies and small scale retorts without off-gas cleaning system or flares, releasing the unburnt by-products as emissions. These kilns generate multiple hazardous emissions by the incomplete combustion of the feedstock, such as PM, VOC, $\mathrm{NO}_{x}$ and $\mathrm{CO}[24,182]$ as summarized in Table 3 . Some advanced charcoal kilns partly condense the VOC by a chimney and use these as a value-added by-product [25]. VOC can be subdivided into methane and non-methane organic compounds [182]. PM are increased from incomplete combustion of especially dried feedstock, whereas feedstock with high moisture content increases smoke formation [183]. Highest PM emissions occur in the first hours after the under-stoichiometric combustion is initiated [10]. Large PM emissions in combination with deforestation can result in a net increase in global warming potential [182] and must therefore be inhibited.

About $3-3.6 \%$ of the biomass carbon is emitted as condensable liquid emissions from simple kilns [182]. Polycyclic aromatic hydrocarbons (PAH) are one class of these products which are partly considered as hazardous to health and environment [184,185], and are mainly emitted in the first hours of the wood carbonization process [10]. 5.0 to $7.6 \%$ of total PAHs or 82 to $100 \%$ of the aromatics with 5 to 6 rings are found within the PM $[10,184]$. The number of PAHs in pyrolysis off-gases is higher than that of complete biomass combustion [10]. The concentration of dust including PM can range from 1.77 to $38.9 \mathrm{mg} \mathrm{m}^{-3}$ at highest concentration of total dust [186]. About $2.8 \mathrm{mg} \mathrm{m}^{-3}$ of particle bound PAH is smaller than the total emission of gaseous PAHs, which accounted to $23.6 \mathrm{mg} \mathrm{m}^{-3}$ [10]. Maximum concentration of $64-100 \mathrm{mg} \mathrm{m}^{-3}$ have been detected in the initial phase of the pyrolysis process $[10,186]$.

$\mathrm{NO}_{x}$ emissions are dependent on the nitrogen content of the original feedstock. $60-80 \%$ of the nitrogen involved in the pyrolysis exists as protein nitrogen in the biomass, resulting in the formation of $\mathrm{N}$-containing compounds at lower heating rates [187]. A high concentration of lignin promote to formation of $\mathrm{NO}_{x}$ [187]. The amount of $\mathrm{NO}_{x}$ emissions can range between 0.016 to $11 \mathrm{~g}$ per $\mathrm{kg}$ of charcoal $[24,182]$. Sulfur of the parental biomass will be partly released as $\mathrm{SO}_{x}$ emissions. About one-third of the sulfur is released as emissions with the volatiles in carbonization of coal [16]. Sulfur content of biomass transited from mostly sulfate to organosulfur from $500^{\circ} \mathrm{C}$ to $850^{\circ} \mathrm{C}$ [188]. However, sulfur content in wood biomass is generally low.

$\mathrm{CO}$ and $\mathrm{CO}_{2}$ emissions are formed by incomplete combustion and thermal decomposition of the biomass. Carbon monoxide emissions are reported in the range of 130 to $373 \mathrm{~g} \mathrm{~kg}^{-1}$ of charcoal [24,182]. Approximately $25 \%$ of the biomass carbon is converted to $\mathrm{CO}_{2}$, resulting in an emission factor between 543-3027 $\mathrm{g} \mathrm{CO}_{2}$ per $\mathrm{kg}$ of charcoal for the different kiln technologies [182]. The maximum of $3.03 \mathrm{~kg}$ of $\mathrm{CO}_{2}$-equivalent per $\mathrm{kg}$ charcoal is produced in earthmound kilns. The 100 year global warming potential is stated to $1.144-5.685 \mathrm{~kg}$ of $\mathrm{CO}_{2}$-equivalent per $\mathrm{kg}$ charcoal [189]. However, $\mathrm{CO}_{2}$ emissions can be accounted as $\mathrm{CO}_{2}$ neutral for the sustainable biomass production. On average, 28 to $61 \%$ of the $\mathrm{CO}_{2}$ emissions are referred to the charcoal production process, whereas 29 to $61 \%$ arise from the biomass production [189]. Thus, a sustainable biomass production and utilization of the by-products are essential to reduce anthropogenic $\mathrm{CO}_{2}$ emissions in metallurgy, whereas an increased carbon conversion efficiency and recirculation of volatiles are the most important improvements to reduce the pyrolysis gas emissions into the atmosphere [68].

More than $80 \%$ of the volatile emissions from simple charcoal kilns can be reduced by using a chimney and afterburner [24], which are usually installed in advanced kilns such as Brazilian Beehive kiln and Missouri kiln [25]. Industrial retort systems such as Degussa retort, Lambiotte retort etc. are closed systems that use off-gas scrubber and other gas cleaning systems in addition. Thus, modern charcoal production retorts do not pollute the environment compared to their simple 
predecessor [190] and generally fulfill the regulations for industrial emissions in Europe and North-America.

Table 3. Possible emissions from charcoal production in kiln technologies.

\begin{tabular}{ccccccc}
\hline Emission Source & $\mathbf{P M}$ & VOC & $\mathbf{N O}_{x}$ & $\mathbf{C O}$ & $\mathbf{C O}_{\mathbf{2}}$ & Source \\
\hline \multicolumn{7}{c}{$\mathbf{k g ~ t o n}^{-\mathbf{1}}$ of charcoal } \\
\hline Uncontrolled & 140 & 125 & 11 & 130 & 500 & {$[24]$} \\
combustion & $110(\mathrm{PM}+\mathrm{VOC})$ & - & - & - & {$[10]$} \\
& $13-41$ & $24-124$ & $0.0014-0.13$ & $143-373$ & $500-3000$ & {$[182]$} \\
& - & 81 & 0.3 & 210 & - & {$[6]$} \\
& $420-690$ & $34-100$ & $2.7-5.9$ & $340-620$ & $1400-3350$ & {$[191]$} \\
Retort kiln & $20-200$ & $10-99$ & $0.1-0.7$ & $19-89$ & $2600-6000$ & {$[192]$} \\
& $100-300$ & $10-50$ & $0.8-2.8$ & $100-220$ & $1750-2150$ & {$[191]$} \\
& $<1$ & $<1$ & 0.2 & 0.1 & - & {$[6]$} \\
\hline
\end{tabular}

\subsection{Post-Treatment Processes}

Charcoal produced from feedstock of differing particle size showed various chemical properties. Small feedstock particles increase the rate of volatile escape, and the charcoal has an increased ash content $[92,193]$. The charcoal (or biocarbon) can be post-treated to adjust its properties and to utilize additional by-product streams, such as fine material or bio-oil. The ash content of charcoal is about 3 to 4 times larger than that of biomass due to the devolatilization of the organic volatile matter. Post treatment processes like water- and acid-leaching can be used to reduce the final ash content of the charcoal as described above $[59,99,194]$. A large extent of fine particles is produced during transport and handling of charcoal. Briquetting, pelletizing and agglomeration can be used to compact charcoal fines and to produce a renewable reductant with increased properties [124], such as mechanical strength and density $[150,180,195,196]$. Densification processes vary by energy consumption and can impact the chemical and physical properties of the charcoal [124].

A balance between mechanical strength and porosity of charcoal has to be found for the use of bioreductants in ferroalloy industries. Charcoal is often porous (both micro- and macroporous), which is disadvantageous when carbon needs to be mechanically stable and not excessively reactive, as it is the case in manganese production. The micropores in charcoal can be closed by the deposition of carbon from methane that could ease the transition to the use of biocarbon as a means of metal ore reduction [28,197]. In addition, properties of the original feedstock such as density, moisture content, heating value, ash content, and compressive strength affect the quality of charcoal and pellets/briquettes made from charcoal. Therefore, process route of the raw feedstock and by-products is a dominating factor governing properties of charcoal and bioreductant-based pellets/briquettes in the reduction furnace.

The possible method for preparing charcoal-based reductants is to compact fine charcoal particles with the addition of a binder. The fines can be agglomerated to improve the mechanical properties of charcoal-based reductants by adding water and organic binder i.e molasse [172], starch [195], lignin [124,198] and bio-oil [63,150]. The binder is required due to the lack of plasticity of charcoal particles compared to untreated biomass. The binder forms solid bridges between particles, resulting in an improved mechanical stability of the densified product [172]. Starch in combination with water are superior to bio-oil based on its availability and low economical value [195]. Lignin softens at temperature above $140^{\circ} \mathrm{C}$ and forms agglomerates between charcoal particles [124,198,199], in which hardwood lignin is superior to softwood lignin due to the greater amount of methoxy content [199]. Lignin is commercially available as a by-product from second generation bio-fuels [150] and from pulping industry [199].

Mechanical properties are affected by the added binder, its content and compacting pressure. The mechanical strength of carbon briquettes can be increased by increasing the binder content to $6.5-8.6 \mathrm{wt}$.\% of softwood and hardwood lignin [199]. An increased bio-oil ratio from 10 to 
$40 \%$ resulted in an increased compression strength by approximately $50 \%$ after a second heat treatment [150]. The second heat treatment reduced the volatile matter from the pellets and resulted in cross-linking of the bio-oil and charcoal particles and improved the mechanical strength of charcoal pellets and briquettes $[105,200,201]$. Lignin and bio-oil were successfully tested as binders for heat treatment temperatures up to $1100^{\circ} \mathrm{C}[150,199]$. To ensure a high mechanical stability at higher temperatures, metallic silicon can be added as an additive to the binder-charcoal mixture [199]. Overall, charcoal producents strive for the use of small charcoal particles in pelletizing process without further milling to keep the cost of the overall bioreductant process low. Further heat treatments can be used to reduce the volatile matter content and to improve mechanical strength of the lump charcoal, pellets and briquettes $[105,200,201]$.

However, charcoal pellets can reduce a self-heating risk when the operating temperature in the furnace exceeds $600^{\circ} \mathrm{C}$ [180]. In addition, porosity and surface area decreased after charcoal pelletizing using the pyrolysis bio-oil, whereas the use of coal tar as a binder did not affect the combustion and physicochemical properties of pellets made from fossil-based reductants [202]. Coal tar is a type of toxic, hazardous and carcenogenic solid waste generated in the process of coal gasification or coking and composed of heavy tar oil, pulverised coal and particles in gases produced in coal pyrolysis [203,204]. Therefore, renewable and carbon-neutral binders i.e., bio-oil with the addition of paraffin oil, castor oil, mineral oil and linseed oil can be an alternative to fossil-based binders due to the increased energy density of charcoal pellets with the low self-heating risk [205].

\section{Charcoal}

Charcoal is comprised of the unconverted organic solids, the non-volatile mineral matter and the carbonized products. Fixed carbon content of charcoal is generally greater than $70 \%[5,73]$, and it is considered greater than $85 \%$ for metallurgical grade charcoal $[5,152]$. The feedstock origin and the pyrolysis conditions are the main influencing parameter on the physicochemical properties $[156,206]$. The obtained structure of charcoal is defined by the original feedstock, particle size and heating rate, in which pyrolysis at slow heating rates and larger particles results in the similar charcoal structure compared to its feedstock [206]. Charcoal produced from dense hardwood provide a greater mechanical stability than charcoal produced from softwood, which is preferable in the ferroalloy industry [152]. The electrical properties of charcoal are also important for the use as a reductant in SAF.

The charcoal yield of classical kiln production processes is in the range of 5 to $20 \mathrm{wt} . \%$ on dry basis due to the limited control of process conditions (e.g., air supply) [8]. These production processes release often large quantities of unburnt hydrocarbons to the atmosphere, and provide a fixed carbon content in the range of 65 to $80 \%$ [25]. Industrial retorts on the other hand provide charcoal yields of $\approx 35 \%[207,208]$, whereas charcoal yields up to $62 \%$ were reported for pilot scale experiments $[153,209]$. Thus, the conversion efficiency of the carbonization process is one of the key issues for a sustainable process chain [7].

\subsection{Yields}

The charcoal yield from industrial charcoal production is summarized in Table 4. Carbon efficiency of modern retorts is about twice greater than that of earth mound kilns, and achieve a yield of about $35 \mathrm{wt} . \%$ on dry basis $[6,43]$. Well operated Brazilian kilns with tar recovery provided a similar charcoal yield with up to $36.4 \%$ and carbon yield of $69 \%$ [182]. In charcoal kilns, the required thermal energy is provided by the partial combustion of wood, its by-products and other fuels i.e., gas, oil, etc. [25]. The combustion of by-products and wood can decrease the charcoal yield to less than $20 \%$. The modernized energy efficient kilns include the bio-oil condensation units and can obtain higher charcoal yields than it was reported for traditional kilns [6,182].

Charcoal yield from pyrolysis of "dead" biomass is similar to "living" biomass, whereas the bio-oil yield is approximately $1 \%$ greater for dead biomass at the cost of pyrolysis gases [210]. Thus, charcoal yield from sapwood at short rotation forestry ( $\leq 20$ years) is similar to stem wood (sapwood and 
heartwood) from classical forestry (50-150 years cycle). The low solid yield in fast pyrolysis indicates a limited potential of charcoal use in ferroalloy industries [74,101,177,179]. However, bio-oil utilization as a binder or an electrode material using fast pyrolysis opens new opportunities for the process upscale in ferroalloy industries.

To estimate the usable carbon fraction for metallurgical application, yield and fixed carbon content of charcoal were combined in the fixed carbon yield. The fixed carbon yield is defined as: $\gamma_{F C}=\gamma \cdot(F C) \cdot(1-a)^{-1}$, where $\gamma_{F C}$ is the fixed carbon yield, $\gamma$ is the charcoal yield, FC is the fixed carbon content of the charcoal and $a$ is the ash content of the biomass $[1,209,211]$. The fixed carbon yield of charcoal varies from 20 to $30 \mathrm{wt}$.\% on dry basis $[155,208]$. Bio-oil utilization can increase $\gamma_{F C}$ by $4-5 \%$-points $[63,105]$. Herbaceous biomass such as sugarcane has a lower conversion efficiency than wood pyrolysis, resulting in a lower bio-oil yield and lower exergy efficiency than that of wood pyrolysis on area basis despite its greater growth rate [212].

Table 4. Charcoal yield for the pyrolysis of biomass.

\begin{tabular}{|c|c|c|c|c|c|}
\hline \multirow{2}{*}{ Biomass } & \multirow{2}{*}{ Pyrolysis Process } & \multirow{2}{*}{$\begin{array}{c}\text { Charcoal Yield } \\
\text { /wt. } \%\end{array}$} & \multirow{2}{*}{$\frac{\text { Temperature }}{{ }^{\circ} \mathrm{C}}$} & \multirow{2}{*}{$\begin{array}{c}\text { Firing Time } \\
/ \mathrm{h}\end{array}$} & \multirow{2}{*}{ Source } \\
\hline & & & & & \\
\hline Wood & Small scale pyrolyzer & $18-40$ & $400-700$ & $0.1-6$ & {$[40,155,213]$} \\
\hline Biomass waste & Small scale pyrolyzer & $14-45$ & $390-900$ & $0.5-3$ & [214-216] \\
\hline Herbaceous biomass & Small scale pyrolyzer & $18-48$ & $400-700$ & $0.1-35$ & {$[155,217]$} \\
\hline Biomass & Pressurized small scale reactor & $35-40$ & $500-650$ & $<0.5$ & {$[1,218]$} \\
\hline \multirow[t]{3}{*}{ Biomass } & Fast pyrolysis (small scale) & 23-35 & $450-650$ & $<0.01$ & {$[35,217]$} \\
\hline & Fast pyrolysis (industrial) & combusted & $500-550$ & $<0.001$ & [219] \\
\hline & Fluidized bed & $18-25$ & n.s. & $<0.001$ & [25] \\
\hline Hardwood & Charcoal kilns & $9-34.2$ & $450-600$ & 80 & {$[6,25,73,182]$} \\
\hline Blend & Rectangular kiln & $27-31$ & $450-650(700)$ & $96-120$ & [220] \\
\hline Cord wood & Kiln & $8-9$ & n.s. & $<6$ & [221] \\
\hline Hardwood & Missouri kiln & $20-30$ & $450-550$ & $80-144$ & {$[25,161,182]$} \\
\hline \multirow[t]{3}{*}{ Hardwood } & Brick kiln & $15-25$ & $450-600$ & 80 & {$[25,73]$} \\
\hline & Keyan earthmound kiln & $21-34$ & n.s. & $170-235$ & [182]. \\
\hline & Hot-tail kiln & 38 & n.s & $40-50$ & [182]. \\
\hline \multirow[t]{3}{*}{ Beechwood } & Retort & $30-38$ & $450-550$ & $11-22$ & {$[25,73]$} \\
\hline & Twin-retort & 33 & 500 & 12 & [6] \\
\hline & CML process & $22-24$ & 500 & $6-8$ & [161] \\
\hline Biomass & DPC technology & 34 & 500 & $6-20$ & [161] \\
\hline
\end{tabular}

\subsection{By-Products}

Volatile pyrolysis products are accounted as by-products from charcoal production. Volatiles are composed of light pyrolysis gases, such as $\mathrm{CO}, \mathrm{CO}_{2}, \mathrm{CH}_{4}, \mathrm{H}_{2}$ and light hydrocarbons [222,223], and condensable liquids, such as organic acids, methanol, heavy hydrocarbons, oxygenates, etc. [43,61]. The liquid products are defined as bio-oil, which is composed of more than 300 compounds with an oxygen content between 35 and $40 \%$ and heating value of 11 to $26 \mathrm{MJ} \mathrm{kg}^{-1}$ [223,224]. Water content of slow pyrolysis bio-oil is more than twice larger than that of fast pyrolysis oil [225] and strongly affected by the initial moisture content of the biomass feedstock. The high water content of slow pyrolysis bio-oil 50\% [63,225] can lead to a phase separation, which generally occurs for bio-oils with a water content larger than 30-35\% under storage [222]. This emphasizes the importance of dried biomass feedstock, since the moisture content increases the bio-oil yield and decreases the concentration of the organic fraction and its heating value. A moisture content less than $45-50 \%$ is required for an autothermal operation [226], respectively less than 20-25\% for an efficient and stable operation of industrial scale retorts, such as the Lambiotte process $[6,68]$.

The major organics in bio-oil are organic acids, alcohols (e.g., methanol: 1.4-7.9\%), oxygenates (e.g., acetone: $0.3-1.6 \%$ ) and tars (11.8-26.6\%) [61]. Most of the compounds are water soluble, while $15-35 \%$ of bio-oil is water insoluble $[227,228]$. Chemical composition analysis of the water insoluble fraction showed a carbon content of $50-71 \%$, hydrogen content of $5.8-6.7 \%$ and oxygen content of $23-43 \%$ [227,229]. The high oxygen content facilitates ageing reactions in the bio-oil, leading to an increased viscosity and average molecular weight from 530 to $990 \mathrm{~g} \mathrm{~mol}^{-1}$ [230]. In addition, 
the low pH-value (2-3) of bio-oil increases the maintenance cost for the condenser and storage system [224]. PAHs were found in bio-oil within a range of 10 to $50 \mathrm{mg} \mathrm{kg}^{-1}$ [231], which are accounted as harmful to the environment [185]. However, only one-third to two-third of the biooil compounds can been identified by GC-MS and HPLC [227,232].

About $10-20 \%$ of pyrolysis gas is formed by pyrolysis of biomass at temperatures up to $800^{\circ} \mathrm{C}[43,225,233]$. The yield of pyrolysis gas increases with increasing heat treatment temperature and can be $75 \%$ at $1200^{\circ} \mathrm{C}$ [154]. Its composition is strongly affected by heat treatment temperature and operation of the kiln or retort. The pyrolysis gas in charcoal production is mainly composed of $\mathrm{H}_{2}(\leq 20.1 \%) ; \mathrm{CH}_{4}(5-22.0 \%) ; \mathrm{CO}(30.1-58 \%) ; \mathrm{CO}_{2}(22.5-43 \%)$ and light hydrocarbons $\mathrm{C}_{x} \mathrm{H}_{y}$ $(2.3 \%)[210,222,223]$. $\mathrm{CO}$ and $\mathrm{CO}_{2}$ concentrations are increased in classical charcoal production by the partly combustion of additional feedstock, whereas $\mathrm{H}_{2}$ concentration would increase at high heat treatment temperature by dehydrogenation reaction and carbonization of the charcoal [234]. Unburnt pyrolysis gas can therefore be accounted as a strong pollutant based on the high $\mathrm{CO}$ and $\mathrm{CH}_{4}$ concentration [5]. However, the gas can have a heating value of $8000 \mathrm{~kJ} \mathrm{~m}^{-3}$ [5], respectively $2.3 \mathrm{MJ} \mathrm{kg}^{-1}$ [161]. Therefore, the released volatiles during pyrolysis can be combusted to provide the thermal energy for the process [5].

\subsection{By Product Utilization}

Pyrolysis of biomass results in the formation of $50 \%$ of liquid and $20 \%$ of gaseous by-products. In current processes, by-products can be combusted to provide the thermal energy of the process, increasing the amount of (renewable) $\mathrm{CO}_{2}$ emissions at the same time. Unburnt by-products reduce the process efficiency and lead to net GHG emissions. Industrial retorts on the other hand recirculate the volatile compounds and can condensate parts as value-added by-products for consecutive processes [25]. Recent studies have shown that the charcoal yield can be increased by up to $5 \%$-points by the bio-oil recirculation [63]. Pressurized retorts decompose a large fraction of the bio-oil inside the charcoal particles $[157,158]$, decreasing the yield of high molecular hydrocarbons in the bio-oil.

The high molecular bio-oil can be used as feedstock material for green electrodes, as a feedstock in gasification, as a binder for briquetting or pelletizing or as fuel for boilers according to EN 16900, i.e., as standardized, readily marketable product $[180,181]$. Briquetting and pelletizing enable a conditioning of charcoal fines at the pyrolysis plant and thus, increase the carbon yield suitable in ferroalloy industry. In addition, the homogeneity of charcoal briquettes and pellets is increased. Green electrodes have successfully been produced from fast pyrolysis bio-oil [181], but composition of bio-oil from fast pyrolysis differs from that of slow pyrolysis [225,235]. The high water content and the large fraction of organic acids, such as acetic and propionic acid, inhibit a direct usage as engine fuel [61]. Distillation of the tarry compounds will result in the formation of $35-50 \%$ of solid residues [224] and is only limited applicable for the bio-oil conditioning. Recent studies focus on the bio-oil upgrading with in-situ generation of hydrogen [236].

Gasification of bio-oil can provide a synthetic gas for fuel and chemical production $[237,238]$. Some bio-oil components have established markets which were supplied by coke oven batteries and other pyrolysis processes before products were synthesized by natural gas and other fossil fuels, such as acetic acid. Bio-oil conditioning may provide renewable chemicals which can directly substitute fossil fuels in the future. In short term, bio-oil as a binder can increase the charcoal yield and concurrently reduce waste streams.

\section{Charcoal Properties}

Properties of charcoal are crucial for the use as a reductant in metallurgical processes [16,18]. To minimize changes in a process design and optimization, charcoal properties are expected to be similar to those of fossil-based reductants, as summarized in Table 5. Fossil-based reductants show high mechanical stability and low to medium gas reactivity at a low price, whereas charcoal has a high gas reactivity and low mechanical stability. In addition, charcoal has a lower density than fossil-based 
reductants, that may change the mass flow and volume distribution of the raw materials in the SAF. Charcoal is produced in large proportions by kilns as a household fuel that does not require specific properties. However, the quality of charcoal produced in kilns can significantly vary from one batch to another.

Understanding mechanical, chemical, physical and electrical properties of charcoal is a key step that affects the use of charcoal in ferroalloy industries $[16,18,29,239]$. Mechanical strength is required to avoid collapse of the carbon bed by the load of the burden, while abrasive strength (or durability) is required to minimize generation of fines while handling and feeding of charcoal particles into the reactor [239]. Chemical properties such as carbon content and reactivity are essential to provide the carbon in the reaction zone, while ash content and composition of the feedstock can affect the product quality and energy demand [172]. Electrical properties are crucial for the quality of carbon bed material in the SAF to provide the thermal heat by electrical energy dissipation.

Table 5. Required properties of carbon reductants in the ferro and ferroalloy industry [29,239-245].

\begin{tabular}{ccccc}
\hline \multirow{2}{*}{ Property } & \multirow{2}{*}{ Unit } & \multirow{2}{*}{ Blast Furnace } & \multicolumn{2}{c}{ Ferroalloy } \\
\cline { 4 - 5 } & & & Silicon & Manganese \\
\hline Moisture & {$[\%]$} & $1-6$ & $\leq 6$ & $\leq 6$ \\
Fixed carbon & {$[\%]$} & $\geq 85$ & $\geq 84$ & $\geq 85$ \\
Volatile matter & {$[\%]$} & $\leq 1.5$ & $\leq 9.5$ & $\leq 3$ \\
Ash & {$[\%]$} & $\leq 12$ & $\leq 12$ & $\leq 12$ \\
Phosphorous & {$[\%]$} & $\leq 0.06$ & $<0.02$ & $<0.02$ \\
Sulfur & {$[\%]$} & $\leq 0.9$ & $\leq 0.6$ & $\leq 0.6$ \\
Size & {$\left[\mathrm{mm}^{-3}\right]$} & $47-70$ & $5-40$ & $5-40$ \\
Bulk density & {$\left[\mathrm{kg} \mathrm{m}^{-3}\right]$} & & $400-500$ & $400-500$ \\
Ash fusion temperature & {$\left[{ }^{\circ} \mathrm{C}\right]$} & & $1250-1450$ & $1250-1450$ \\
CSR & {$[\%]$} & $\geq 60$ & - & - \\
CRI & {$[\%]$} & $20-30$ & - & - \\
\hline
\end{tabular}

\subsection{Chemical Analysis}

While the charcoal yield is the most important variable for its production, specific charcoal properties are compulsory for its application. The chemical analysis comprises the proximate and ultimate analyses, as well as the structural properties. The carbonization degree increases with increasing heat treatment temperature, resulting in an greater fixed carbon content of the charcoal. The carbonization results in structural changes of the carbon matrix, affecting functional group and reactivity of the sample.

\subsubsection{Proximate and Ultimate Analyses}

Carbon content increases with increasing heat treatment temperature and residence time. Classical charcoal production results in a carbon content greater than 70\% [161]. The proximate analysis of classical charcoal production is shown in Table 6 . Based on the biomass feedstock, industrial retorts provide a carbon content of $80-94 \%$ [6,37]. Charcoal with a fixed carbon content greater than $83 \%$ is considered as barbecue charcoal according to EU requirements [6] and as metallurgical grade charcoal with a fixed carbon content greater than $85 \%$ [152]. A fixed carbon content greater than $85 \%$ is therefore recommended in ferroalloy production to minimize additional slag formation by ash constituents and off-gas cleaning by volatile matter [239]. Metallurgical coke used in a closed SAF has a volatile matter content less than $3 \mathrm{wt} . \%$ (generally $1-1.5 \%$ [246,247]), whereas more than $10 \%$ of volatiles are released by charcoal samples. Volatile matter content of charcoal pellets is increased to more than $24 \%$ by the addition of water and binder $[105,172,247]$. This high volatile matter content requires an improved off-gas cleaning system and increases the risk of slag foaming in secondary steelmaking routes [248]. One possibility to reduce volatile matter content similar to metallurgical coke is to use the secondary heat treatment at temperatures of $1300{ }^{\circ} \mathrm{C}$ [63]. 
The ash content of charcoal is correlated to the ash content of the feedstock. Therefore, the ash content is low for stem wood charcoal and relatively high for charcoal from herbaceous biomass i.e., wheat straw, rice husks, etc. $[38,155]$. Ash content with more than $8-12 \mathrm{wt} . \%$ should be avoided in SAF to reduce the amount of impurities and generated slag [239]. Biomass ash is rich in alkali and alkali earth metals compared to fossil fuels, but low in sulfur content. An increased input of alkali metals can cause corrosion issues in the off-gas system and change reduction stages in the burden [172].

Table 6. Proximate analysis of industrially produced charcoal.

\begin{tabular}{cccccc}
\hline \multirow{2}{*}{ Reactor } & Biomass & Ash & $\begin{array}{c}\text { FC } \\
\text { wt.\% }\end{array}$ & VM & Source \\
\hline & Wood & $0.4-4$ & $65-85$ & $15-35$ & {$[36,37]$} \\
Kiln & Wood & 1.9 & $84.7(*)$ & & {$[249]$} \\
Kiln & Mangrove & 1.66 & 67.53 & 29.15 & {$[161]$} \\
Kiln & Rain Tree & 1.79 & 78.52 & 18.22 & {$[161]$} \\
Twin-retort & Rubber & 4.67 & 78.98 & 15.24 & {$[161]$} \\
\hline \multicolumn{7}{c}{ Hardwood and softwood } & - & $92 \% *$ & - & {$[6]$} \\
\hline \multicolumn{7}{c}{ * based on ultimate analysis. } \\
\end{tabular}

\subsubsection{Structural Analysis}

The carbon structure of charcoal is highly affected by the heat treatment temperature and the surrounding atmosphere, for example gasification agents or oxygen. The higher carbonization degree at higher heat treatment temperature results in a decreased $\mathrm{CO}_{2}$ reactivity and increased electrical conductivity [1]. Torrefaction and low pyrolysis of biomass on the other hand only slightly increase the carbonization degree. The cellulose peak can be still observed by XRD analysis after a heat treatment at $\approx 340{ }^{\circ} \mathrm{C}$ [220].

Charcoal produced at $240^{\circ} \mathrm{C}$ exhibited the same FT-IR bands as biomass, whereas specific bands of cellulose, hemicellulose and aromatic ring groups from lignin disappeared after a heat treatment temperature of $400^{\circ} \mathrm{C}$ [250]. This change in chemical composition started at temperatures above $350^{\circ} \mathrm{C}$ [251]. A uniform spectra with strong aryl carbon signals indicated poly-condensation of aromatic rings at temperatures above $500^{\circ} \mathrm{C}$ [220], in which fast pyrolysis char showed a lower aromaticity compared to classical charcoal from slow pyrolysis. In addition, these results correspond to mass loss curves from the thermogravimetric analysis [155,172].

Charcoal structure is different from fossil fuel reductants and graphite. The charcoal structure is characterized by the greater surface area and absorptive capacity than carbon black or graphite [40]. Structural changes in coal graphitization occur mainly in four temperature ranges, $1000-1500^{\circ} \mathrm{C}$, $1500-2000{ }^{\circ} \mathrm{C}, 2000-2500^{\circ} \mathrm{C}$ and $2500-3000^{\circ} \mathrm{C}[252,253]$. The basic structural units reorganize between 800 and $1500^{\circ} \mathrm{C}$ and coalesce between 1600 to $2000^{\circ} \mathrm{C}$ [253]. A nano-crystalline structure of charcoal was observed at heat treatment temperatures larger than $1300^{\circ} \mathrm{C}[62,200]$. This temperature range is above the production temperature of industrial charcoal, but structural changes will appear in the burden and carbon bed inside SAF. Charcoal produced at temperatures above $1000^{\circ} \mathrm{C}$ exhibited a similar structure to petroleum coke [254]. The increased graphitization with increasing heat treatment temperatures improves the electrical properties of the charcoal.

\subsection{Density and Porosity}

The density and porosity are important properties for the handling, transport and storage of bulk and compacted charcoal. Density of charcoal is highly affected by the feedstock and process conditions, in which pyrolysis of softwood results in a charcoal with a lower density compared to hardwood. Density of parental wood increases with age [255], resulting in a superior charcoal from older wood. However, due to the easier and less labor-intensive handing of young growth fresh wood, secondary forestry is commonly used as a feedstock in charcoal production [11]. A greater particle density results in improved mechanical and electrical properties, which are important properties for the 
renewable reductant. The skeletal density of charcoal produced at temperatures up to $500{ }^{\circ} \mathrm{C}$ is similar to that of the parental wood $(\approx 1400-1550) \mathrm{kg} \mathrm{m}^{-3}[220,256]$. Above $500{ }^{\circ} \mathrm{C}$, skeletal density starts to increase with increasing heat treatment temperature $[155,208,257]$ to $\approx 1750 \mathrm{~kg} \mathrm{~m}^{-3}$ at $700{ }^{\circ} \mathrm{C}[258]$ and to $\approx 2000 \mathrm{~kg} \mathrm{~m}^{-3}$ at $800^{\circ} \mathrm{C}[220]$.

While true density increases with increasing heat treatment temperature, charcoal's bulk density is nearly constant in the temperature range from 450 to $650^{\circ} \mathrm{C}[257,258]$, leading to a greater BET surface area and porosity compared to low temperature treated charcoal. Metallurgical grade charcoal has a bulk density of 180 to $350 \mathrm{~kg} \mathrm{~m}^{-3}[36,37,201]$, about half of that for metallurgical coke $\left(450-600 \mathrm{~kg} \mathrm{~m}^{-3}\right)[36,37,239,246]$, leading to higher transport and storage costs. In addition, the lower density of charcoal increases the volume fraction of the carbon reductant in the SAF, possibly decreasing the maximum load of the furnace by its available construction height.

The porosity of charcoal increased from $\approx 50 \%$ at $300{ }^{\circ} \mathrm{C}$ to $50-70 \%$ at temperatures above $700{ }^{\circ} \mathrm{C}[155,259]$. The porosity of spruce charcoal was about $10 \%$ points larger than that of oak charcoal [62] and similar to that of grass charcoal [258] and other woody biomass species [123]. On the other hand, total porosity of metallurgical coke ranges from 25 to $62 \%$, increasing with larger particle size $[18,62,239]$. It is known from cokes that the porous structure can affect the mechanical strength of particles [260]. While a relationship between tensile strength and pore structure of coke was determined in previous studies [261], no clear correlation was found for the mechanical strength and porosity by other authors[262].

Bulk density of charcoal can be increased to $900 \mathrm{~kg} \mathrm{~m}^{-3}$ by agglomeration and compaction [172], in which an increased particle density is achieved by blending with an organic binder and increased compaction pressure [124,150]. The addition of organic binder such as lignosulphonate and bio-oil significantly improved the density and mechanical durability of charcoal pellets [150]. A further increase in a bulk density was reported by the increased residence time of pellets and briquettes during compaction [124]. An apparent density of about $1000 \mathrm{~kg} \mathrm{~m}^{-3}$ was reported for charcoal produced under a compressive pressure of $500 \mathrm{kPa}$, that was similar to that of metallurgical coke [259]. On the other hand, the addition of $5 \%$ sawdust to a coal blend resulted in a slightly decreased bulk density of coke, from $780 \mathrm{~kg} \mathrm{~m}^{-3}$ for metallurgical coke to $770 \mathrm{~kg} \mathrm{~m}^{-3}$ for bio-coke [262].

\subsection{Surface Area}

Operation of SAF is affected by the gas reactivity of the carbon material in the burden due to the reaction with $\mathrm{CO}_{2}$ and $\mathrm{SiO}$. The gas reactivity depends on the accessible surface area and presence of functional groups on the surface. The morphology of charcoal is highly affected by the heat treatment temperature, residence time and gas pressure [263]. The specific surface area increased from $5 \mathrm{~m}^{2} \mathrm{~g}^{-1}$ at $300{ }^{\circ} \mathrm{C}$ to $80 \mathrm{~m}^{2} \mathrm{~g}^{-1}$ at $500-600{ }^{\circ} \mathrm{C}[32,264-266]$ and further to $500 \mathrm{~m}^{2} \mathrm{~g}^{-1}$ at $800-900{ }^{\circ} \mathrm{C}[99,213]$. Above $1000^{\circ} \mathrm{C}$, the specific surface area of charcoal decreased to about $10 \mathrm{~m}^{2} \mathrm{~g}^{-1}[62,99]$. The increase in surface area was correlated to the increase in micro- and mesoporosity and the collapse of micropores thereafter $[32,263]$.

Charcoal produced at intermediate pyrolysis pressure (10 bar) showed a smaller surface area than charcoal generated at low pressure (5 bar), respectively high pyrolysis pressure (20 bar) [263]. Yang et al. reported that the surface area decreased with increasing heating rate [35] and was generally lower for herbaceous charcoal than for woody charcoal [32]. The results indicate that the release and secondary pyrolysis reactions of volatile matter has a high impact on the surface area of charcoal. Fossil fuel reductants, such as metallurgical coke, bio-coke and petroleum coke, exhibit a surface area of less than $3 \mathrm{~m}^{2} \mathrm{~g}^{-1}[21,63,267]$. Metallurgical coke and bio-cokes are produced at temperatures above $1100^{\circ} \mathrm{C}$, while petroleum coke is the solidified residue from crude oil distillation. Differences in the accessibility were observed for the surface characterization in $\mathrm{N}_{2}$ and $\mathrm{CO}_{2}$. Surface area from oak and pine charcoal increases from less than $3 \mathrm{~m}^{2} \mathrm{~g}^{-1}$ at $400{ }^{\circ} \mathrm{C}$ to $220-280 \mathrm{~m}^{2} \mathrm{~g}^{-1}$ at $650{ }^{\circ} \mathrm{C}$ for measurements in $\mathrm{N}_{2}$, respectively from 250 to $530 \mathrm{~m}^{2} \mathrm{~g}^{-1}$ for oak and 360 to $650 \mathrm{~m}^{2} \mathrm{~g}^{-1}$ for pine in 
$\mathrm{CO}_{2}$ [268]. Thus, the accessibility of gas species into the pore volume can also affect the reactivity in different atmospheres.

\subsection{Mechanical Properties}

Mechanical properties of charcoal are essential to avoid generation of fine particles by transport, handling and feeding into the SAF. The furnace operation and off-gas cleaning system are significantly affected by the particle size of original feedstock and charcoal [18]. In general, charcoal is more fragile than fossil fuels samples due to its high porosity and lower carbonization degree [253]. Global charcoal transport results in the generation of 5-20\% fines [159,269-271] due to the loading and unloading of the charcoal [271]. This material is not directly suitable for a usage in SAF, since a particle size of $5-40 \mathrm{~mm}$ is required for ferroalloy industry to ensure a good gas permeability $[29,239]$. In particular, the silicomanganese industry uses fossil fuel reductants with a particle size ranging from 5 to $20 \mathrm{~mm}$ [29]. Thus, particles less than $5 \mathrm{~mm}$ are considered as fines and should be avoided.

Standard tests for measuring the mechanical properties are drum tests, such as ASTM D 294-64, ISO 556 and DIN 5171 for coke, and DIN EN ISO 17831-1 for pellets and briquettes. In addition, mechanical fragmentation is investigated by the drop shatter test for coal according to ASTM D440. Hot strength of metallurgical coke is investigated by the coke strength after reaction (CSR). The combination of hot strength and $\mathrm{CO}_{2}$ reactivity are important parameters to evaluate the quality of reductants in the burden [37], especially for blast furnaces. However, most of the standards are not applicable for charcoal and have therefore been modified by the researchers $[36,37]$.

While a very high compression strength is required in blast furnaces, mechanical strength is of less importance in SAF due to the low height of the burden $[40,239]$. Compressive strength of charcoal is $10-80 \mathrm{~kg} \mathrm{~cm}^{-2}$, about half of that of metallurgical coke $\left(130-160 \mathrm{~kg} \mathrm{~cm}^{-2}\right)[36,201]$. Charcoal produced from hardwoods have generally a greater mechanical strength than charcoal from softwood or herbaceous biomass [152] and the mechanical strength is 3 to 4 times greater in the growing direction of wood fibers compared to its perpendicular direction [36]. The compression strength slightly increased after the sample was heat treated to elevated temperatures [201,272], indicating improved mechanical properties inside the SAF. Carbonized wood is about $28 \%$ stronger than its biomass precursor [273].

\subsection{Charcoal Compaction}

Charcoal produced at elevated temperatures has a lower tendency to agglomerate compared to raw biomass and requires the addition of a binder for compaction [123]. Charcoal fines can be compacted by pelletization and briquetting to increase bulk density and mechanical stability for the use in metallurgical industry [124,172,274]. Coal tar, coal tar pitch and bio-oil pitch have been used as binder for special purposes over decades [271]. Recent studies have confirmed that the mechanical properties can be improved for charcoal pellets and briquettes by the addition of bio-oil and bio-oil pitch and a second heat treatment $[63,150,275]$. The mechanical durability of the pellets increased to greater than 90\% [150], similar to that of heat treated hydrochar pellets [129]. Pellets compacted at $116 \mathrm{MPa}$ with an oil concentration of $34 \%$ provided optimal pelletizing conditions [180]. A slightly better mechanical durability was achieved by adding water and molasses at a compaction pressure of $100 \mathrm{MPa}$ [172]. One of the major disadvantages of molasses is the addition of mineral matter (especially potassium) to charcoal pellets and briquettes. Other important parameter are particle size and moisture content, and the glass transition temperature for lignocellulosic binder [124]. Drop strength tests approved the results from mechanical durability test for charcoal pellets [172].

The compressive strength of charcoal pellets increased from less than $1 \mathrm{MPa}$ to greater than $2 \mathrm{MPa}$ after the secondary heat treatment [150]. A similar compressive strength was reported for charcoal briquettes using bio-oil binder [275]. The mechanical compression resistance of green pellets produced with molasses as a binder increased from $1 \mathrm{MPa}$ to $2.6 \mathrm{MPa}$ after storage for 12 days [172]. Similar values were found for fossil fuel briquettes compacted at $56 \mathrm{kPa}$ [199], in which a higher 
compaction pressure resulted in improved mechanical properties and hardwood lignin developed twice the compressive strength than softwood lignin. Lignin as a binder was improved by adding tannic acid, in which the mechanical strength was also obtained as hot strength for temperatures up to $1400^{\circ} \mathrm{C}$ [199]. A compressive strength of 4.2 MPa was reported for briquettes using starch binder [275], which was similar to that of charcoal pellets using bio-oil binder [150]. To ensure mechanical strength at higher temperatures, silicon metal can be added to the charcoal fines, forming a network of silicon carbide nanowires between the carbon matrix [276]. The carbide nanowires improved the resistance to compaction from $1 \mathrm{MPa}$ to 3-4 MPa at $1200-1400{ }^{\circ} \mathrm{C}$ [199].

Pellets started to shrink after the primary heat treatment temperature was surpassed [142]. This additional size reduction must be considered if the particle size of charcoal pellets is close to the minimum particle size requirements. Pellets from fast pyrolysis and slow pyrolysis differ by its aromaticity and volatile matter content [172], leading to differences in a shrinkage at higher temperature. If lignin is selected as binder, a secondary heat treatment temperature above $450{ }^{\circ} \mathrm{C}$ should be chosen to form polyaromatic structures between the particles [277]. The additional heat treatment at elevated temperature also reduces the risk of self-heating under transport and storage [274] and decreases $\mathrm{CO}_{2}$ reactivity [142]. In summary, the quality of pellets and briquettes is highly improved by the second heat treatment.

\subsection{Electrical Properties}

The electrical conductivity is one of the most important properties of carbon reductants in SAF and EAF $[239,253,278]$. The electrical conductivity of charcoal is affected by the heat treatment temperature (carbonization degree), density of the packed bed, particle size and volume fraction of carbon, as well as operating temperature and pressure inside the furnace $[1,201,253,279,280]$. Metallurgical coke used in SAF is expected to have an electrical resistivity of 7-10 $\mathrm{m} \Omega \mathrm{m}$ at room temperature and $1-10 \mathrm{~m} \Omega \mathrm{m}$ at $1400^{\circ} \mathrm{C}$ for a particle size of $5-20 \mathrm{~mm}[37,239,280]$. Charcoal on the other hand has an electrical resistivity above $10^{6} \Omega \mathrm{m}$ at room temperature, decreasing to $14-23 \mathrm{~m} \Omega \mathrm{m}$ at $1000^{\circ} \mathrm{C}$ and $9-18 \mathrm{~m} \Omega \mathrm{m}$ at $1400-1600{ }^{\circ} \mathrm{C}$ for $5-35 \mathrm{~mm}$ respectively $5-10 \mathrm{~mm}$ particles $[37,201]$. The electrical resistivity of charcoal particles from a heat treatment at $950^{\circ} \mathrm{C}$ was similar to that of fossil fuel coal char ranging from 1.7 to $3.4 \mathrm{~m} \Omega \mathrm{m}$ [281].

The electrical resistivity of packed carbon beds is higher than that of particles due to larger contact resistance between particles $[279,282]$. Electrical resistivity of metallurgical coke decreased from $10-15 \mathrm{~m} \Omega \mathrm{m}$ at $1000^{\circ} \mathrm{C}$ to $5-8 \mathrm{~m} \Omega \mathrm{m}$ at $1600^{\circ} \mathrm{C}[37,201]$. Packed beds of charcoal particles larger than $2 \mathrm{~mm}$ showed an electrical resistivity of $50 \mathrm{~m} \Omega \mathrm{m}$ at $1100{ }^{\circ} \mathrm{C}$ and $15-20 \mathrm{~m} \Omega \mathrm{m}$ at $1600{ }^{\circ} \mathrm{C}[37,201]$. The electrical resistivity of metallurgical coke decreased by $50 \%$ when the particle size increased from 5-10 $\mathrm{mm}$ to $15-20 \mathrm{~mm}$ [280]. However, the previous results have also shown that only minimal differences were observed for small and large sizes of charcoal particles [201]. The compaction pressure of the burden has a large impact on the electrical resistivity. An increased compaction pressure decreases the air gap between particles and increases the number of contact points between the particles, resulting in a decreased electrical resistivity $[18,201,279,283]$.

The loss in ohmic resistance can be attributed to the removal of oxygen groups by carbonization from the carbon matrix [252,284], especially at temperatures less than $950{ }^{\circ} \mathrm{C}$. The high oxygen content and disordered carbon structure act as insulators in the carbon matrix of biomass, charcoal and coal [1,285-287], in which a decrease in electrical resistivity of 5 orders of magnitude was observed after the release of volatile matter [1,288]. Therefore, electrical resistivity of carbon reductants can be correlated to the ordering of the carbon matrix and its reactivity [281]. The higher electrical resistivity of charcoal inhibits the conduction of current through the burden inside the SAF [288,289], where $\approx 5-15 \%$ of current is conducted through [18]. In addition, the higher electrical resistivity of the charcoal enables a lower electrode tip position, which improves heat distribution in the lower part of SAF [280]. 


\subsection{Gas Reactivity}

Gas reactivity of carbon reductants is an important property for the burden in SAF. About $30 \%$ of the $\mathrm{CO}_{2}$ emission from ferro-managnese and silicomanganese production are related to the Boudouard reaction $\left(\mathrm{C}(\mathrm{s})+\mathrm{CO}_{2} \rightleftharpoons 2 \mathrm{CO}\right.$ ) [290], indicating the importance of a low gas reactivity towards $\mathrm{CO}_{2}$. A high reaction rate will increase the coke and power consumption and is therefore undesirable in silicomanganese and ferromanganese production [36]. The $\mathrm{CO}_{2}$ reactivity of metallurgical coke is investigated according to coke reactivity index (CRI), where the mass loss is measured by difference after a $2 \mathrm{~h}$ heat treatment $\left(1100^{\circ} \mathrm{C}\right)$ in pure $\mathrm{CO}_{2}$. The standard can not directly be adopted for charcoal samples due to its high gas reactivity. By AC-method, charcoals reactivity can be 30 to 40 times larger compared to metallurgical coke [36]. Many researchers investigate the $\mathrm{CO}_{2}$ reactivity by thermogravimetric analysis at lower temperature, lower $\mathrm{CO}_{2}$ concentration or by non-isothermal analysis $[37,63,204,291,292]$. In addition, knowledge of the $\mathrm{CO}_{2}$ reactivity can be adopted from fixed bed biomass gasification for syngas production [293].

The $\mathrm{CO}_{2}$ reactivities of metallurgical coke and charcoal samples produced at $1060^{\circ} \mathrm{C}$ were compared. Carbon conversion of metallurgical coke was in the order $(0.2-0.5) \cdot 10^{-2} \% \mathrm{C} \mathrm{s}^{-1}$, and thus, about 5 to 16 times lower than that for industrial and laboratory charcoal that ranged from (2.1-3.2) $10^{-2} \% \mathrm{C} \mathrm{s}^{-1}$ ) [37]. Similar results were obtained by other researchers [105,204], in which charcoals from forest residues and herbaceous biomass generally have a higher reactivity than those from stem wood [204]. $\mathrm{CO}_{2}$ reactivity of charcoal samples post treated at temperatures larger than $1600{ }^{\circ} \mathrm{C}$ approached that of fossil fuel reductants [62,99]. Despite the high porosity and surface area of charcoal, $\mathrm{CO}_{2}$ reactivity of charcoal samples decreased by about $20-50 \%$ when the particle size from $60 \mu \mathrm{m}$ to $1-2 \mathrm{~mm}[294,295]$. Previous studies have shown that up to $70 \%$ of the carbon conversion depends on the external surface area and the potassium content in original feedstock [291]. The higher reactivity of carbon fines may improve the stability of SAF by the consumption of small particles in the burden, resulting in an improved gas permeability of the bed.

Alkali and alkali earth metals are stated as catalysts for the Boudouard reaction [158,204,291]. The catalytic index is shown as the quotient of the sum of catalytic elements $(\mathrm{K}, \mathrm{Ca}, \mathrm{Mg}, \mathrm{Na}, \mathrm{Fe})$ to inhibiting elements ( $\mathrm{Si}, \mathrm{Al}$ ) [291]. Bio-based reductants with a low mineral matter content showed a similar reactivity compared to the fossil coke [20]. However, potassium impregnated coke was more reactive than low ash charcoal, but less reactive than potassium impregnated charcoal [36]. These results indicate a dominating role of potassium on the $\mathrm{CO}_{2}$ reactivity, confirming the previous results [97]. In addition, alkali and alkali earth metals can recirculate in the burden, resulting in an accumulation of potassium in the SAF [36]. The $\mathrm{CO}_{2}$ reactivity is also highly affected by $\mathrm{CO}_{2}$ partial pressure [200,296-299]. In addition, the high concentration of CO is desirable for ferroalloy production to pre-reduce higher metal-oxides in the burden and as a value-added product gas for other applications [300,301]. Beside the Boudouard reaction, charcoal also reacts with $\mathrm{SiO}$ gas in silicon and ferrosilicon production. The $\mathrm{SiO}$ reactivity is determined by passing hot $\mathrm{SiO}$ gas ( $13.5 \% \mathrm{SiO}, 4.5 \% \mathrm{CO}$ ) through a carbon bed according to the improved SINTEF procedure, which was developed by Tuset and Raaness in the 1970's and described elsewhere [302]. The SiO gas will react with the carbon reductant according to: $\mathrm{SiO}(\mathrm{g})+2 \mathrm{C}(\mathrm{s}) \rightleftharpoons \mathrm{SiC}(\mathrm{s})+\mathrm{CO}(\mathrm{g})$, thereby forming a solid silicon carbide layer at the surface. Therefore, it can be assumed that the $\mathrm{SiO}$ reactivity is mainly depending on the porosity and accessible surface area of the carbon material, eventually blocking the reaction surface and decreasing $\mathrm{SiO}$ reactivity over time [94]. The general trend is $\mathrm{SiO}$ reactivity of charcoal $\geq$ coal $\geq$ metallurgical coke $\geq$ petcoke $[94,303,304]$. It is also known that about $80 \%$ of the silicon from the gas phase can be recovered in the ferro-silicon production, while $20 \%$ of the $\mathrm{SiO}$ gas is discharged by the off-gases [239]. Therefore, woodchips and charcoal can improve the gas permeability of the burden, prevent the crusting of the charge and increase the recovery of SiO gas [253,305]. 


\subsection{Slag Reactivity}

Reduction of metal-oxide to the pure metals takes place in the liquid state by carbon reductants in the lower part of SAF, for example by the reaction: $\mathrm{MnO}+\mathrm{C} \rightleftharpoons \mathrm{Mn}+\mathrm{CO}$. Carbon can be provided as solid carbon at the contact point between the slag and the "coke" bed, and by the dissolution of carbon into the liquid metal. The sessile drop wettability test [306] and thermogravimetric analysis (TGA) at $1600{ }^{\circ} \mathrm{C}$ [37] are techniques to evaluate the slag-carbon reactivity in ferroalloy industries. Thus, slag reactivity can be characterized by its dissolution and by the reaction kinetics [253]. In the former, the slag reactivity is depending on the dissolution rate of the carbon material into the liquid metal phase. Alkali metals in charcoal can decrease the carbon solubility into the liquid metal. It is known from carbon dissolution into liquid iron that $\mathrm{S}, \mathrm{P}, \mathrm{Si}, \mathrm{Al}, \mathrm{Ni}$ and Co decrease the solubility of carbon, whereas $\mathrm{Mn}$ and $\mathrm{Cr}$ slightly increase it [253]. Charcoal and fossil coke can be equally used as reductants in silicomanganese production [36], in which the dissolution rate constant is significantly improved by increasing heat treatment temperature $[37,253]$ due to the increased degree of crystallinity of the carbon matrix [94]. For example, the dissolution rate constants of coal can vary in the range 0.0011 to $0.0036 \mathrm{~s}^{-1}$ [253].

The kinetics of metal-oxides reduction can be investigated by using TGA coupled with an infrared analyzer at temperatures above $1500^{\circ} \mathrm{C}[307,308]$. A high graphitization degree of the carbon matrix is beneficial for the high reaction rate. However, reductants with a low degree of graphitization and large occupying volume fraction tend to have a higher reactivity towards manganese ores due to their large surface area [278]. Coke has a faster slag reactivity than charcoal and much faster than graphite, whereas the highest reactivity of charcoal is observed in alkali lean charcoal samples [309]. However, the kinetics for slag and $\mathrm{MnO}$ reduction can change by the presence of metal phases, such as reduced $\mathrm{FeO}$ and $\mathrm{SiO}_{2}$ [253,309]. Silicon and ferrosilicon production can be accounted as slag free [30], and the main reduction reaction is given by the SiO-reactivity as discussed above. Thus, highest quartz-carbon reactivity can be observed for charcoal and coal [304]. The different tendencies in reactivity of gas-carbon and slag-carbon inhibit a correlation between the two properties [306].

\section{Available Charcoal Technologies}

Charcoal has been produced batch-wise in different kiln technologies since millenia, and some of the old inefficient technologies are still used in developing and newly industrializing countries [8]. In general, charcoal production can be divided into kiln technologies where the heat is provided directly by the partial combustion of additional feedstock, respectively [25]. A schematic of the different heat supply system for charcoal production is shown in Figure2, whereas the production capacity and production rate are summarized in Table 7 . In general, maximum heat treatment temperature for charcoal production in kilns and retorts is between 450 and $650^{\circ} \mathrm{C}[68,161,220]$.

The pits and earthmound kilns are the simplest technologies for the charcoal production. The space capacity of the pits are in the range of 4 to $30 \mathrm{~m}^{3}$ of fuel wood, while earthmound kilns can be enlarged up to a capacity of $150 \mathrm{~m}^{3}$ [25]. Earthmound kilns have been improved in the second half of the 19th century by adding a chimney, and provided large amounts of charcoal for iron smelting industry [25]. The additional chimney enabled a precise control of the air supply by ensuring optimum draught conditions, and resulting in a greater charcoal yield with better properties $[25,310]$. The chimney can also act as an air cooler to condense heavy hydrocarbons, acids and water, which are value-added by-products from pyrolysis process and improve the control of the kiln. Chidumayo estimated that it is unlikely to futher increase the charcoal production rate of $23.3 \%$ in earthmound kilns [311]. Brick kilns have been used and improved over the last decades. The Missouri kilns provide a volume capacity of $180-800 \mathrm{~m}^{3}$ and a charcoal yield of $20-30 \%[160,161]$, about twice than that of classical earthmound kilns. The cycle time of these kilns is typically in the range from 7 to more than 30 days $[11,160,226]$. Largest kilns have a capacity of $2000 \mathrm{~m}^{3}$ and can produce 10,000 tons of charcoal per year [161]. 
Most of the charcoal in the EU is produced in steel retorts [161]. Biomass carbonization is thereby carried out in continuously operated processes, such as the Lambiotte retort, which is used since 1942 with a production capacity of 2000-9000 tons of charcoal per year [68]. Heat treatment temperature in Lambiotte retort is $600^{\circ} \mathrm{C}$ in the carbonization zone [68]. Other technologies, such as the Carbon engineering technology are operated at $500^{\circ} \mathrm{C}$ that is similar to the maximum temperature in kilns [161,220]. A horizontal retort (also called Twin-retort) has been developed in the 1990s by Norit B.V., in which multiple retorts can be combined to increase production rate and reduce emissions [6]. Similar technologies are the VMR systems with two retorts and one central combustion chamber and a production rate of 6000-7000 tons per year [226]. Other retorts are Reichert retort, Lurgi/Degussa process, Nichols-Herreshoff Process and the rotative furnace $[8,25]$. Carbonex is the most recent process, combining the pyrolysis unit with a $1.4 \mathrm{MW}$ power production [161]. The largest industrial charcoal plants produce about $25,000-27,000$ tons of charcoal annually $[207,208]$.

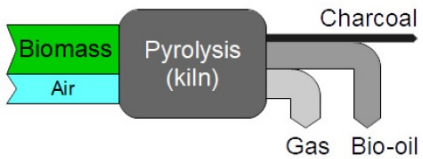

Internal heating

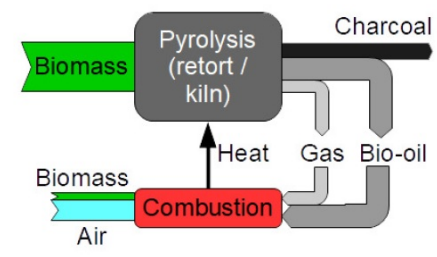

External heating

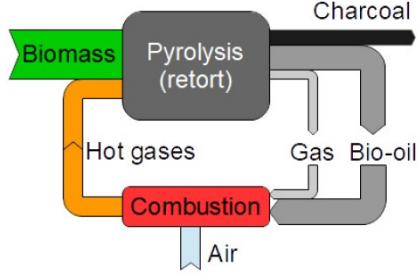

Heating with recirculating volatile matter / gas

Figure 2. Possible heating systems in charcoal production (after [25,29]).

Table 7. Charcoal production technologies.

\begin{tabular}{|c|c|c|c|}
\hline Brand or Technology & Size & Production Rate [mg/year] & Sources \\
\hline \multicolumn{4}{|l|}{ Kilns } \\
\hline Earthmound kilns & $9.5 \mathrm{~m}^{3}$ & $945 \mathrm{~kg}$ per cycle & [11] \\
\hline Earthmound kilns & $400-32,000 \mathrm{~m}^{3}$ & & [182] \\
\hline \multirow[t]{2}{*}{ Egyptian process } & \multirow{2}{*}{\multicolumn{2}{|c|}{$\begin{array}{l}3-7 \text { tons per cycle ( } 2-3 \text { weeks duration }) \\
1-2 \text { tons per cycle ( } 3-5 \text { weeks cvcle) }\end{array}$}} & [5] \\
\hline & & & [5] \\
\hline Double wall kiln & $1 \mathrm{~m}^{3}$ & \multirow{5}{*}{10 tons per cycle } & [5] \\
\hline Reactangular kiln & 64-106 & & [220] \\
\hline Brazilian rectangular with tar recovery & $80,000 \mathrm{~m}^{3}$ & & {$[182]$} \\
\hline Brazilian round brick (with chimney) & $20,000 \mathrm{~m}^{3}$ & & {$[182]$} \\
\hline Brazilian hot-tail (no chimney) & $4000 \mathrm{~m}^{3}$ & & {$[182]$} \\
\hline Rima Container Kiln (semi-continuous) & & 1 ton/hour & [160] \\
\hline \multicolumn{4}{|l|}{ Retorts } \\
\hline VMR & \multirow{5}{*}{$3 \mathrm{~m}^{3}$ of solid wood } & $6000-7000$ & [226] \\
\hline Twin-retort & & $900-11,000$ & [6] \\
\hline CML (12 retorts) & & $2000-3000$ & [161] \\
\hline DPC technology & & $3000-15,000$ & [161] \\
\hline CK-1 EKKO (mobile kiln) & & $300-600$ & [161] \\
\hline Lambiotte process & $16.3 \mathrm{~m}$ height, $600 \mathrm{~m}^{3}$ volume & $2000-8000$ & [68] \\
\hline
\end{tabular}

\subsection{Economics}

Charcoal markets are established in Africa, Asia and South-America, where charcoal is the primary fuel source to urban and rural households. The largest wood charcoal markets in 2018 were Brazil, Ethiopia and Zambia, with a total market size of about 6.7 billion US dollars [312]. This charcoal was often produced by earthmound kilns at a low efficiency, but also at low costs [311]. Due to the low capital expenditures (CapEx) and operating expenses (OpEx), the economics of such charcoal production is mainly driven by the charcoal market prices and capacity factor for charcoal production [6]. The charcoal production in the EU countries is always highly affected by the investment costs, OpEx and biomass price, such as energy saving and production efficiency [166]. Charcoal price of 250 Euro per ton of 
charcoal in 2002 was required to cover investment costs of about 500,000 Euro [6]. However, the cost of the biomass feedstock is one of the major obstacles for charcoal or bio-oil production [172].

Sweden, Norway and Finland have large unused potential of forest areas available for wood production, e.g., 19.6 million ha in Finland [313] or about 10-15 million $\mathrm{m}^{3}$ in Norway [200]. Cornifer roundwood, such as spruce and pine, are the main wood species in the northern countries, accounting for more than $75 \%$ of the annual harvest [313,314]. Some sawlogs may not provide the strength characteristics for a construction industry and can be considered as a possible feedstock for charcoal production [313]. There is a deficit of biomass mobilization and only limited integration of biomass resources in other industrial sectors [26], which is also valid for global roundwood markets with a total global trade volume of 135 million $\mathrm{m}^{3}$ (7\% of industrial roundwood production) [313]. The limited market integration can lead to the fluctuations in prices and can also inhibit investment in new technologies or methods to produce charcoal, whereas the metallurgical industry can be a large scale customer for renewable reductants over the long term.

Bio-refineries can improve the economics of charcoal production routes by enabling integrated value-added products at reduced fuel prices, and can be a possible key for future commercialization [315]. Bio-fuel production, which is well integrated in Europe, can establish the first stage of a bio-refinery [60], and the solid residues from the emerging bio-fuel markets can be used as feedstock for metallurgical grade charcoal production. The principles of bio-refinery can improve the overall economics by utilizing the complete feedstock or minimizing waste stream generation [316]. Charcoal can be extracted from bio-crude production, which would result in an increased number of decentralized pyrolysis plants to cover the bio-fuel product stream [317]. Bio-oil can be processed and specific compounds can be separated and used as value-added products [178]. For example, a natural smoke was extracted and commercialized by Ensyn as a food additive, whereas acetic acid can be used by chemical industry to produce vinyl acetate or ethyl acetate [178].

Charcoal production in developing countries is often carried out by unskilled operators in pits and earthmound kilns without a licence [221]. In some countries more than $75 \%$ of energy demand are covered by firewood and charcoal $[318,319]$. However, the income is especially important for households with loss agricultural capacity and limited stocks [318] and can account for more than $2 \%$ of GDP of the country [221]. Although the cost share of licensing is very low, sustainable wood sourcing requires the adequate governmental regulations to reflect the sustainability of a sustainable secondary forestry [7]. Certification of charcoal by Programme for the Endorsement of Forest Certification (PEFC), Forest Stewardship Council (FSC) or European Biochar Certificate (EBC) can help to distinguish between sustainable charcoal produced from secondary forestry and charcoal produced from wood made from primary forestry. Modern technologies can also increase the conversion efficiency and reduce the risk of local pollution, while long term contracts can ensure a stable price range for local charcoal producers and the ferroalloy industry.

\section{Discussion}

Charcoal has been used in the metallurgical industry over millenia and is partly used in the ferroalloy industry, such as silicon and silicomanganese production in Brazil. Typical reductants used for the silicon production are coal, petroleum coke and charcoal, while woodchips are used to ensure a good gas permeability in the burden [23]. Thus, fossil fuel reductants and renewable reductants are considered as carbon sources in silicon metal production [320]. Woodchips and charcoal may fully replace fossil-based reductants when their properties are comparable with the requirements for the use in open furnaces, e.g., reactivity, mechanical abrasion and mechanical strength. Minimum requirements vary by ferroalloy production and furnace type, in which reactivity toward $\mathrm{CO}_{2}$ and dissolution rate into the metal are important parameters for ferromanganese and ferrochromium production, whereas $\mathrm{SiO}$ reactivity is important for ferrosilicon and ferrochromium reduction [94]. The high volatile matter content of classical charcoal is larger than $10 \mathrm{wt} . \%$ resulting in off-gas cleaning issues in closed hearth furnaces during reduction of manganese ferroalloys (both FeMn and SiMn). 
Charcoal fines can cause two types of problem. Charcoal fines can reduce the gas permeability in the burden, resulting in an unstable operation of the furnace. Another challenge is that charcoal fines can be carried over into the gas cleaning system by the generated gases. Transport and handling can result in a fines generation up to $20 \%$, which are not suitable in SAF. Charcoal pellets mixed with the bio-oil binder showed similar mechanical properties without an impact on the $\mathrm{CO}_{2}$ reactivity to that of fossil-based coke. The use of organic binders i.e., molasses or starch resulted also in high mechanical stable pellets and briquettes [275]. However, the high ash content in molasses i.e., K, Na, Ca can interact with the organic compounds in other organic binders. The disadvantage of charcoal pelletization is the requirement to comminute particles. Briquettes can be produced from fines without additional milling and with satisfactory mechanical properties for the ferroalloy industry. The secondary heat treatment is required to ensure the high mechanical stability of charcoal-based pellets or briquettes.

The large volatile matter content and high $\mathrm{CO}_{2}$ reactivity of charcoal may cause problems in the burden of SAF. The structural and chemical properties, mineral matter composition of the charcoal can be adjusted using post-treatment processes [291]. While volatile matter content decreases with increasing pyrolysis temperature, the ash content increases inversely proportional to the release of volatile matter. The increased ash content in charcoal may inhibit the use of alkali rich feedstock i.e., wheat straw, rice husks, bark, etc. In addition, the high alkali metal content of charcoal may cause problems in the upper part of the SAF where alkali metals tend to accumulate. In addition, different post-treatment processes, such as acid leaching and high temperature treatment, have shown that the ash content and reactivity of charcoal can be optimized approaching properties of fossil fuel reductants.

Currently, most of the charcoal is produced in developing countries and is locally used for heating and cooking. An increased global demand can be covered in a certain range, but a sustainable production may be limited due to the availability of energy efficient retorts or kilns. Earthmound kiln and pits can emit harmful emissions and pollute local environment by unskilled operators, such as local farmers involved in the unlicensed charcoal production. Deforestation and inefficient charcoal production can finally result in the net GHG emissions and should then be avoided as a substitute to fossil-based reductants. Certificated charcoal or charcoal from certified producers can reduce the risk of charcoal from primary forestry, e.g., by Forest Stewardship Council (FSC) or European Biochar Certificate (EBC). In the long term, modern charcoal retorts can produce high quality charcoal at high conversion efficiency, ensuring an income for farmers and operators at a stable price.

Charcoal production in Europe can ensure a sustainable biomass production and efficient charcoal manufacturing. However, the lack of market integration and fluctuation of feedstock prices may inhibit investments in new technologies. Bio-refineries can combine the production of chemicals, fuels and reductants. Recent research has shown that properties of charcoal were not negatively affected by recovering value-added compounds before pyrolysis, for example waxes, steroids or fatty acids. The liquid by-product from pyrolysis can be used as a binder to enlarge the charcoal yield with the limited influence on the $\mathrm{CO}_{2}$ reactivity.

\section{Summary}

Charcoal can be considered as a renewable reducing agent for the ferroalloy industry. Retorts operated at $550-600^{\circ} \mathrm{C}$ produce a charcoal with a fixed carbon content greater than $85 \%$, in which pyrolysis by-products are utilized to provide the thermal heat for the process. Charcoal produced under these conditions can directly be used in open hearth furnaces for the ferrosilicon and silicon production. The high $\mathrm{SiO}$ reactivity of charcoal makes it a superior reductant compared to coal, semi-coke or coke. However, the mechanical properties of charcoal are generally inferior to fossil-based reductants, resulting in up to $20 \%$ losses of fines by handling and transport. In addition, the compressive strength of charcoal is half compared to metallurgical coke, but still sufficient to withstand the mechanical load by the burden in SAF.

Charcoal fines can be densified through pelletization or briquetting using organic binder such as bio-oil, starch or lignin to reduce waste streams. It was shown that the mechanical properties of 
densified charcoal are improved by a second heat treatment and would also withstand the load of the burden in SAF. The organic binders i.e., bio-oil are preferred over the inorganic binders due to the impact of alkali matter content on the reactivity and mechanical strength of charcoal samples. The high potassium content in charcoal may be a hurdle, since it catalyzes the Boudouard reaction. Acid leaching of biomass feedstock or charcoal can reduce the potassium content, and in combination with a high temperature treatment, concurrently adjust $\mathrm{CO}_{2}$ reactivity that approaches properties of fossil-based reductants. A secondary heat treatment at temperatures above $1100{ }^{\circ} \mathrm{C}$ is required to reduce the volatile matter content to below $1.5 \%$.

Charcoal production in developing countries is only sustainable in a certain range. An additional charcoal demand is expected to increase local prices, possibly leading to a larger charcoal production using primary forestry. This can result in a short-term deforestation and charcoal production by inefficient technologies. Certification such as European Biochar Certificate (EBC) can reduce the risk of primary forestry and inefficient charcoal production. Using certified charcoal can substantially contribute to the reduction of anthropogenic $\mathrm{CO}_{2}$ emissions from ferroalloy industry.

Harvesting cycles of 10 years can provide a metallurgical grade charcoal with the properties approaching that of currently used fossil-based reductants. Large potential of wood is available in Norway, Sweden and Finnland. However, the high CapEx and OpEx for classical charcoal production inhibit local charcoal development. Bio-refineries can provide high value-added chemicals for the energy and chemical sector with the concurrent production of charcoal used by metallurgical industries.

Author Contributions: Conceptualization, G.R.S., A.T. and M.T.; methodology, G.R.S.; validation, G.R.S., A.T. and M.T.; writing—original draft preparation, G.R.S.; writing-review and editing, G.R.S., A.T. and M.T.; visualization, G.R.S.; supervision, M.T.; project administration, M.T.; funding acquisition, M.T. All authors have read and agreed to the published version of the manuscript.

Funding: This research was funded by Research Council of Norway grant number 280968. The APC was funded by Norwegian University of Science and Technology.

Acknowledgments: The authors gratefully acknowledge the financial support from Research Council of Norway (Project Code: 280968) and our industrial partners Elkem ASA, TiZir Titanium \& Iron AS, Eramet Norway AS, Finnfjord AS and Wacker Chemicals Norway AS for financing KPN Reduced $\mathrm{CO}_{2}$ emissions in metal production project.

Conflicts of Interest: The authors declare no conflict of interest.

\section{Abbreviations}

The following abbreviations are used in this manuscript.

$\begin{array}{ll}\text { a } & \text { Ash } \\ \text { BF } & \text { Blast furnace } \\ \text { CapEx } & \text { Capital expenditures } \\ \text { CCS } & \text { Carbon capture and storage } \\ \text { CHL } & \text { Cellulose, hemicellulose and lignin } \\ \text { CRI } & \text { Coke reactivity index } \\ \text { CSR } & \text { Coke strength after reaction } \\ \text { EAF } & \text { Electric arc furnace } \\ \text { FC } & \text { Fixed carbon } \\ \text { FeMn } & \text { Ferromanganese } \\ \text { GDP } & \text { Gross domestic product } \\ \text { GHG } & \text { Green house gases } \\ \text { HC FeCr } & \text { High carbon ferrochrome } \\ \text { HC FeMn } & \text { High carbon ferromanganese } \\ \text { HTC } & \text { Hydrothermal carbonization } \\ \text { OpEx } & \text { Operating expenses } \\ \text { PAH } & \text { Polycyclic aromatic hydrocarbons } \\ \text { PM } & \text { Particulate matter } \\ \text { SAF } & \text { Submerged arc furnace } \\ \text { ScCO } & \text { Supercritical CO }{ }_{2} \text { extraction } \\ \text { SiMn } & \text { Silicomanganese } \\ \text { TGA } & \text { thermogravimetric analysis } \\ \text { VM } & \text { Volatile matter } \\ \text { VOC } & \text { Volatile organic compounds } \\ \gamma & \text { yield } \\ & \end{array}$




\section{References}

1. Antal, M.J.; Grønli, M. The Art, Science, and Technology of Charcoal Production. Ind. Eng. Chem. Res. 2003, 42, 1619-1640. [CrossRef]

2. Hummel, R.E. The First Materials (Stone Age and Copper-Stone Age). In Understanding Materials Science; Springer: New York, NY, USA, 2004.

3. Gallagher, R.M.; Ingram, P. New Coordinated Science: Chemistry Students' Book: For Higher Tier; New Coordinated Science-3rd Edition for Higher Tier; Oxford University Press: Oxford, UK, 2001; Volume 3.

4. Klavina, K.; Karklina, K.; Blumberga, D. Charcoal production environmental performance. Agron. Res. 2015, 13, 511-519.

5. Gomaa, H.; Fathi, M. A simple charcoal kiln. In Proceedings of the ICEHM2000, Giza, Egypt, 9-12 September 2000; pp. 167-174.

6. Reumerman, P.J.; Frederiks, B. Charcoal production with reduced emissions. In Proceedings of the 12th European Conference on Biomass for Energy, Industry and Climate Protection, Amsterdam, The Netherlands 17-21 June 2002; pp. 1-4.

7. African Forestry and Wildlife Commission. Sustainable Charcoal Production for Food Security and Forest Landscape Restoration; Report Number FO:AFWC/2020/4.2; Food and Agriculture Organization of the United Nations: Rome, Italy, 2020; pp. 1-6.

8. Muylaert, M.S.; Sala, J.; de Freitas, M.A.V. The charcoal's production in Brazil-Process efficiency and environmental effects. Renew. Energy 1999, 16, 1037-1040. [CrossRef]

9. Nabukalu, C.; Gieré, R. Charcoal as an Energy Resource: Global Trade, Production and Socioeconoic Practices Observed in Uganda. Resources 2019, 8, 183. [CrossRef]

10. Mara dos Santos Barbosa, J.; Ré-Poppi, N.; Santiago-Silva, M. Polycyclic aromatic hydrocarbons from wood pyrolyis in charcoal production furnaces. Environ. Res. 2006, 101, 304-311. [CrossRef] [PubMed]

11. Coomes, O.T.; Burt, G.J. Peasant charcoal production in the Peruvian Amazon: rainforest use and economic reliance. For. Ecol. Manag. 2001, 140, 39-50. [CrossRef]

12. Carrari, E.; Ampoorter, E.; Bottalico, F.; Chirici, G.; Coppi, A.; Travaglini, D.; Verheyen, K.; Selvi, F. The old charcoal kiln sites in Central Italian forest landscapes. Quat. Int. 2017, 458, 214-223. [CrossRef]

13. Edenhofer, O.; Madruga, R.; Sokona, Y.; Minx, J.; Farahani, E.; Kadner, S.; Seyboth, K.; Adler, A.; Baum, I.; Brunner, S.; et al. Climate Change 2014 Mitigation of Climate Change: Working Group III Contribution to the Fifth Assessment Report of the Intergovernmental Panel on Climate Change; Pacific Northwest National Lab. (PNNL): Richland, WA, USA, 2014.

14. World Steel Association. Steel's Contribution to a Low Carbon Future and Climate Resilient Societies-Worldsteel Position Paper; World Steel Association: Brussels, Belgium, 2017.

15. Balomenos, E.; Panias, D.; Paspaliaris, I. Energy and Exergy Analysis of the Primary Aluminum Production Processes: A Review on Current and Future Sustainability. Miner. Process. Extr. Metall. Rev. 2011, 32, 69-89. [CrossRef]

16. Olsen, S.E.; Tangstad, M.; Lindstad, T. Production of Manganese Ferroalloys; Tapir Akademisk Forlag: Trondheim, Norway, 2007; p. 247.

17. Holappa, L. Basics of Ferroalloys. In Handbook of Ferroalloys-Theory and Technology; Butterworth-Heinemann: Oxford, UK, 2013; pp. 9-28.

18. Eidem, P.A. Electrical Resistivity of Coke Beds. Ph.D. Thesis, NTNU, Trondheim, Norway, 2008.

19. Dhainaut, M. Simulation of the electric field in a submerged arc furnace. In Proceedings of the Infacon $X$, Cape Town, South Africa, 1-4 February 2004; pp. 605-613.

20. Ng, K.W.; MacPhee, J.A.; Giroux, L.; Todoschuk, T. Reactivity of bio-coke with $\mathrm{CO}_{2}$. Fuel Process. Technol. 2011, 92, 801-804. [CrossRef]

21. Seo, M.W.; Jeong, H.M.; Lee, W.J.; Yoon, S.J.; Ra, H.W.; Kim, Y.K.; Lee, D.; Han, S.W.; Kim, S.D.; Lee, J.G.; et al. Carbonization characteristics of biomass/coking coal blends for the application of bio-coke. Chem. Eng. J. 2020, 394, 124943. [CrossRef]

22. Monsen, B.; Grønli, M.; Nygaard, L.; Tveit, H. The Use of Biocarbon in Norwegian Ferroalloy Production. In Proceedings of the INFACON IX, Quebec City, ON, Canada, 3-6 June 2001; Volume 9, pp. 268-276.

23. Myrvågnes, V. Analyses and Characterization of Fossil Carbonaceous Materials for Silicon Production. Ph.D. Thesis, NTNU, Trondheim, Norway, 2008. 
24. United States Environmental Protection Agency. Charcoal. Wood Products Industry. In AP 42, 5th ed.; Environmental Protection Agency: Washington, DC, USA, 1995; Volume I, Chapter 10. Available online: https: / /www.epa.gov/air-emissions-factors-and-quantification/ap-42-compilation-air-emission s-factors (accessed on 28 September 2020).

25. Emrich, W. Handbook of Charcoal Making: The Traditional and Industrial Methods; Solar Energy R\&D in the Ec Series E; Springer: Berlin/Heidelberg, Germany, 1985.

26. Scarlat, N.; Dallemand, J.-F.; Skjelhaugen, O.J.; Asplund, D.; Nesheim, L. An overview of the biomass resource potential of Norway for bioenergy use. Renew. Sustain. Energy Rev. 2011, 15, 3388-3398. [CrossRef]

27. Norsk Industri. The Norwegian Process Industries' Roadmap-Combining Growth and Zero Emissions by 2050. 2016. Available online: https:/ / www.norskindustri.no/siteassets/dokumenter/rapporter-og-brosjy rer/the-norwegian-process-industries-roadmap-summary.pdf (accessed on 7 December 2018).

28. Dalaker, H.; Ringdalen, E.; Kolbeinsen, L.; Mårdalen, J. Road-Map for Gas in the Norwegian Metallurgical Industry: Greater Value Creation and Reduced Emissions. 2017. Available online: https: / / sintef.brage.unit.no/sintef-xmlui/bitstream/handle/11250/2452079/Road-map\%20for\%20gas\% 20in\%20the\%20Norwegian\%20metallurgical\%20industry.pdf?sequence=6 (accessed on 11 September 2020).

29. Tangstad, M. Ferrosilicon and Silicon Technology; Butterworth-Heinemann: Oxford, UK, 2018.

30. Schei, A.; Tuset, J.K.; Tveit, H. Production of High Silicon Ferroalloys; Tapir Forlag: Trondheim, Norway, 1998.

31. Meng, J.; He, T.; Sanganyado, E.; Lan, Y.; Zhang, W.; Han, X.; Chen, W. Development of the straw biochar returning concept in China. Biochar 2019, 1, 139-149. [CrossRef]

32. Park, J.; Lee, Y.; Ryu, C.; Park, Y.K. Slow pyrolysis of rice straw: Analysis of products properties, carbon and energy yields. Bioresour. Technol. 2014, 155, 63-70. [CrossRef]

33. Carpenter, D.; Westover, T.L.; Czernik, S.; Jablonski, W. Biomass feedstocks for renewable fuel production: A review of the impacts of feedstock and pretreatment on the yield and product distribution of fast pyrolysis bio-oils and vapors. Green Chem. 2014, 16, 384-406. [CrossRef]

34. Henrich, E.; Dinjus, E.; Rumpel, S.; Stahl, R. A Two-Stage Pyrolysis/Gasification Process for Herbaceous Waste Biomass from Agriculture. In Progress in Thermochemical Biomass Conversion; John Wiley \& Sons: Hoboken, NJ, USA, 2008; pp. 221-236.

35. Yang, C.; Li, R.; Zhang, B.; Qui, Q.; Wang, B.; Yang, H.; Ding, Y.; Wang, C. Pyrolysis of microalgae: A critical review. Fuel Process. Technol. 2019, 186, 53-72. [CrossRef]

36. Monsen, B.; Tangstad, M.; Midtgaard, H. Use of charcoal in silicomanganese production. In Proceedings of the Infacon X, Cape Town, South Africa, 1-4 February 2004; Volume 68, pp. 155-164.

37. Monsen, B.; Tangstad, M.; Solheim, I.; Syvertsen, M.; Ishak, R.; Midtgaard, H. Charcoal for manganese alloy production. In Proceedings of the INFACON XI, New Delhi, India, 18-21 February 2007; pp. 297-310.

38. ECN.TNO. Phyllis2, Database for (Treated) Biomass, Algae, Feedstocks for Biogas Production and Biochar. Available online: https: / phyllis.nl/ (accessed on 12 October 2020).

39. Nygård, R.; Elfving, B. Stem basic density and bark proportion of 45 woody species in young savanna coppice forests in Burkina Faso. Ann. For. Sci. 2000, 57, 143-153.

40. Demirbaş, A.; Ahmad, W.; Alamoudi, R.; Sheikh, M. Sustainable charcoal production from biomass. Energy Sources Part A 2016, 38, 1882-1889. [CrossRef]

41. Bassam, N.E. Handbook of Bioenergy Crops; Earthscan Ltd.: London, UK, 2010.

42. Räisänen, T.; Athanassiadis, D. Basic Chemical Composition of the Biomass Components of Pine, Spruce and Birch. 2013. Available online: http://biofuelregion.se/wp-content/uploads/2017/01/1_2_IS_2013-01-3 1_Basic_chemical_composition.pdf (accessed on 15 September 2020).

43. Balat, M. Mechanisms of Thermochemical Biomass Conversion Processes. Part 1: Reactions of Pyrolysis. Energy Sources Part A 2008, 30, 620-635. [CrossRef]

44. Jones, J.R.; Chen, Q.; Ripberger, G.D. Secondary Reactions and the Heat of Pyrolysis of Wood. Energy Technol. 2020, 8, 2000130. [CrossRef]

45. Evans, R.J.; Milne, T.A. Molecular characterization of the pyrolysis of biomass. 1. Fundamentals. Energy Fuels 1987, 1, 123-137. [CrossRef]

46. Broido, A.; Kilzer, F.J. A Critique of the Present State of Knowledge of The Mechanism of Cellulose Pyrolysis. Fire Res. 1963, 5, 157-161.

47. Antal, M.J.; Gábor, V.; Jakab, E. Cellulose Pyrolysis Kinetics: Revisited. Ind. Eng. Chem. Res. 1998, 37, $1267-1275$. [CrossRef] 
48. Collard, F.-X.; Blin, J. A review on pyrolysis of biomass constituents: Mechanisms and composition of the products obtained from the conversion of cellulose, hemicelluloses and lignin. Renew. Sustain. Energy Rev. 2014, 38, 594-608. [CrossRef]

49. Peng, Y.; Wu, S. The structural and thermal characteristics of wheat straw hemicellulose. J. Anal. Appl. Pyrolysis 2010, 88, 134-139. [CrossRef]

50. Shen, D.K.; Gu, S.; Bridgwater, A.V. Study on the pyrolytic behaviour of xylan-based hemicellulose using TG-FTIR and Py-GC-FTIR. J. Anal. Appl. Pyrolysis 2010, 87, 199-206. [CrossRef]

51. Werner, K.; Pommer, L.; Broström, M. Thermal decomposition of hemicelluloses. J. Anal. Appl. Pyrolysis 2014, 110, 130-137. [CrossRef]

52. Branca, C.; Albano, A.; Di Blasi, C. Critical evaluation of global mechanisms of wood devolatilization. Thermochim. Acta 2005, 429, 133-141. [CrossRef]

53. Du, S.; Valla, J.A.; Bollas, G.M. Characteristics and origin of char and coke from fast and slow, catalytic and thermal pyrolysis of biomass and relevant model compounds. Green Chem. 2013, 15, 3214-3229. [CrossRef]

54. Hosoya, T.; Kawamoto, H.; Saka, S. Pyrolysis behaviors of wood and its constituent polymers at gasification temperature. J. Anal. Appl. Pyrolysis 2007, 78, 328-336. [CrossRef]

55. Yang, H.; Yan, R.; Chen, H.; Lee, D.H. Characteristics of hemicellulose, cellulose and lignin pyrolysis. Fuel 2007, 86, 1781-1788. [CrossRef]

56. Zaror, C.A.; Pyle, D.L. The pyrolysis of biomass: A general review. Proc. Indian Acad. Sci. Sect. C Eng. Sci. 1982, 5, 269-285.

57. Trubetskaya, A.; Jensen, P.A.; Jensen, A.D.; Glarborg, P.; Larsen, F.H.; Andersen, M.L. Characterization of free radicals by electron spin resonance spectroscopy in biochars from pyrolysis at high heating rates and at high temperatures. Biomass Bioenergy 2016, 94, 117-129. [CrossRef]

58. Trubetskaya, A.; Jensen, P.A.; Jensen, A.D.; Steibel, M.; Spliethoff, H.; Glarborg, P. Influence of fast pyrolysis conditions on yield and structural transformation of biomass chars. Fuel Process. Technol. 2015, 140, $205-214$. [CrossRef]

59. Persson, H.; Kantarelis, E.; Evangelopoulos, P.; Yang, W. Wood-derived acid leaching of biomass for enhanced production of sugars and sugar derivatives during pyrolysis: Influence of acidity and treatment time. J. Anal. Appl. Pyrolysis 2017, 127, 329-334. [CrossRef]

60. Hoover, A.; Emerson, R.; Williams, C.L.; Ramirez-Corredores, M.M.; Ray, A.; Schaller, K.; Hernandez, S.; Li, C.; Walton, M. Grading Herbaceous Biomass for Biorefineries: A Case Study Based on Chemical Composition and Biochemical Conversion. Bioenergy Res. 2019, 12, 977-991. [CrossRef]

61. Demirbaş, A. Relationships between Carbonization Temperature and Pyrolysis Products from Biomass. Energy Explor. Exploit. 2004, 22, 411-420. [CrossRef]

62. Surup, G.R.; Foppe, M.; Schubert, D.; Deike, R.; Heidelmann, M.; Timko, M.T.; Trubetskaya, A. The effect of feedstock origin and temperature on the structure and reactivity of char from pyrolysis at $1300-2800{ }^{\circ} \mathrm{C}$. Fuel 2019, 235, 306-316. [CrossRef]

63. Surup, G.; Vehus, T.; Eidem, P.A.; Trubetskaya, A.; Nielsen, H.K. Characterization of renewable reductants and charcoal-based pellets for the use in ferroalloy industries. Energy 2019, 167, 337-345. [CrossRef]

64. Pereira, B.L.C.; Carneiro, A.C.O.; Márcia, A.; Colodette, J.; Oliveira, A.; Fontes, M.P.F. Influence of Chemical Composition of Eucalyptus Wood on Gravimetric Yield and Charcoal Properties. BioResources 2013, 8, 4574-4592. [CrossRef]

65. Nielsen, H.K.; Lærke, P.E.; Liu, N.; Jørgensen, U. Sampling procedure in a willow plantation for estimation of moisture content. Biomass Bioenergy 2015, 78, 62-70. [CrossRef]

66. Da Silva, V.M.; Silva, L.A.; de Andrade, J.B.; da Cunha Veloso, M.C.; Santos, G.V. Determination of moisture content and water activity in algae and fish by thermoanalytical techniques. Quim. Nova 2008, 31, 901-905. [CrossRef]

67. Hosseinizand, H.; Sokhansanj, S.; Lim, C.J. Studying the drying mechanism of microalgae Chlorella vulgaris and the optimum drying temperature to preserve quality characteristics. Dry. Technol. 2018, 36, 1049-1060. [CrossRef]

68. Klavina, K.; Klavins, J.; Veidenbergs, I.; Blumberga, D. Charcoal production in a continuous operation retort. Experimental data processing. Energy Procedia 2016, 95, 208-215. [CrossRef] 
69. Bergman, R. Drying and Control of Moisture Content and Dimensional Changes. In Wood Handbook-Wood as an Engineering Material; General Technical Report FPL-GTR-190; USDA Forest Service: Washington, DC, USA, 2010; p. 509.

70. Dong, J.; Chi, Y.; Tang, Y.; Ni, M.; Nzihou, A.; Weiss-Hortala, E.; Huang, Q. Effect of Operating Parameters and Moisture Content on Municipal Solid Waste Pyrolysis and Gasification. Energy Fuels 2016, 30, 3994-4001. [CrossRef]

71. Eke, J.; Onwudili, J.A.; Bridgwater, A.V. Influence of Moisture Contents on the Fast Pyrolysis of Trommel Fines in a Bubbling Fluidized Bed Reactor. Waste Biomass Valoriz. 2020, 11, 3711-3722. [CrossRef]

72. Canal, W.D.; Carvalho, A.M.; Figueiró, C.G.; de Cassia Oliveira Carneiro, A.; de Freitas Fialho, L.; Donato, D.B. Impact of Wood Moisture in Charcoal Production and Quality. Floresta Ambiente 2020, 27, e20170999. [CrossRef]

73. Emrich, W.; Booth, H.; Beaumont, E. Industrial Charcoal Making; Food and Agriculture Organization of the United Nations: Rome, Italy, 1985.

74. Bridgwater, T.; Meier, D.; Radlein, D. An Overview of Fast Pyrolysis of Biomass. Org. Geochem. 1999, 30, 1479-1493. [CrossRef]

75. Yamagishi, K.; Endo, K.; Saga, J. A comprehensive analysis of the furnace interior for high-carbon ferrochromium. In Proceedings of the INFACON I, Johannesburg, South Africa, 22-26 April 1974; pp. 143-147.

76. De Waal, A.; Barker, I.J.; Rennie, M.S.; Klopper, J.; Groeneveld, B.S. Electrical Factors Affecting the Economic Optimization of Submerged-arc Furnaces. In Proceedings of INFACON VI, Cape Town, South Africa, 8-11 March 1992; Volume 1, pp. 247-252.

77. Chahal, A.; Ciolkosz, D. A review of wood-bark adhesion: Methods and mechanics of debarking for woody biomass. Wood Fiber Sci. 2019, 51, 1-12. [CrossRef]

78. Heppelmann, J.B.; Labelle, E.R.; Wittkopf, S.; Seeling, U. In-stand debarking with the use of modifed harvesting heads: a potential solution for key challenges in European forestry. Eur. J. For. Res. 2019, 138, 1067-1081. [CrossRef]

79. Momeni, M.; Yin, C.; Kœr, S.K.; Hansen, T.B.; Jensen, P.A.; Glarborg, P. Experimental Study on Effects of Particle Shape and Operating Conditions on Combustion Characteristics of Single Biomass Particles. Energy Fuels 2012, 27, 507-514. [CrossRef]

80. Momeni, M. Fundamental Study of Single Biomass Particle Combustion. Ph.D. Thesis, Aalborg University, Aalborg, Denmark, 2012.

81. Himmel, M.; Tucker, M.; Baker, J.; Rivard, C.; Oh, K.; Grohmann, K. Comminution of Biomass: Hammer and Knife Mills. Biotechnol. Bioeng. Symp. 1985, 15, 39-58.

82. Paulrud, S.; Mattsson, J.E.; Nilsson, C. Particle and handling chracteristics of wood fuel powder: Effects of different mills. Fuel Process. Technol. 2002, 76, 23-39. [CrossRef]

83. Paulrud, S. Upgraded Biofuels-Effects of Quality on Processing, Handling Characteristics, Combustion and ASH Melting. Ph.D. Thesis, Umeå University, Umeå, Sweden, 2004.

84. Schell, D.J.; Harwood, C. Milling of Lignocellulosic Biomass. Appl. Biochem. Biotechnol. 1994, 46, 159-169. [CrossRef]

85. Mandø, M.; Rosendahl, L.; Yin, C.; Sørensen, H. Pulverized straw combustion in a low $\mathrm{NO}_{x}$ multifuel burner: Modeling the transition from coal to straw. Fuel 2010, 89, 3051-3062. [CrossRef]

86. Miao, Z.; Grift, T.E.; Hansen, A.C.; Ting, K.C. Energy requirement for comminution of biomass in relation to particle physical properties. Ind. Crop. Prod. 2011, 33, 504-513. [CrossRef]

87. Williams, O.; Newbolt, G.; Eastwick, C.; Kingman, S.; Giggings, D.; Lormor, S.; Lester, E. Influence of mill type on densified biomass comminution. Appl. Energy 2016, 182, 219-231. [CrossRef]

88. Masche, M.; Puig-Arnavat, M.; Wadenbäck, J.; Clausen, S.; Jensen, P.A.; Ahrendfeldt, J.; Henriksen, U. Wood pellet milling tests in a suspension-fired power plant. Fuel Process. Technol. 2018, 173, 89-102. [CrossRef]

89. Westover, T.L.; Phanphanich, M.; Clark, M.L.; Rowe, S.R.; Egan, S.E.; Zacher, A.H.; Santosa, D. Impact of thermal pretreatment on the fast pyrolysis conversion of southern pine. Biofuels 2013, 4, 45-61. [CrossRef]

90. Stelte, W.; Sanadi, A.R.; Shang, L.; Holm, J.K.; Ahrenfeldt, J.; Henriksen, U.B. Recent developments in biomass pelletization-A review. BioResources 2012, 7, 4451-4490.

91. Harun, N.Y.; Afzal, M.T. Effect of Particle Size on Mechanical Properties of Pellets Made from Biomass Blends. Procedia Eng. 2016, 148, 93-99. [CrossRef] 
92. Trubetskaya, A.; Beckmann, G.; Poyraz, Y.; Weber, R. Secondary comminution of wood pellets in power plant and laboratory-scale mills. Fuel 2017, 160, 675-683. [CrossRef]

93. Jensen, A.; Dam-Johansen, K.; Wojtowicz, M.A.; Serio, M.A. TG-FTIR study of the influence of potassium chloride on wheat straw pyrolysis. Energy Fuels 1998, 12, 929-938. [CrossRef]

94. Pistorius, P.C. Reductant selection in ferro-alloy production: The case for the importance of dissolution in the metal. J. S. Afr. Inst. Min. Metall. 2002, 1, 33-36.

95. Kong, L.; Tian, S.H.; Li, Z.; Luo, R.; Chen, D.; Tu, Y.; Xiong, Y. Conversion of recycled sawdust into high HHV and low $\mathrm{NO}_{x}$ emission bio-char pellets using lignin and calcium hydroxide blended binders. Renew. Energy 2013, 60, 559-565. [CrossRef]

96. Jensen, P.A.; Sander, B.; Dam-Johansen, K. Removal of $\mathrm{K}$ and $\mathrm{Cl}$ by leaching of straw char. Biomass Bioenergy 2001, 20, 447-457. [CrossRef]

97. Trubetskaya, A.; Larsen, F.H.; Shchukarev, A.; Ståhl, K.; Umeki, K. Potassium and soot interaction in fast biomass pyrolysis at high temperatures. Fuel 2018, 225, 89-94. [CrossRef]

98. Xu, W.; Wei, J.; Chen, J.; Zhang, B.; Xu, P.; Ren, J.; Yu, Q. Comparative Study of Water-Leaching and Acid-Leaching Pretreatment on the Thermal Stability and Reactivity of Biomass Silica for Viability as a Pozzolanic Additive in Cement. Materials 2018, 11, 1697. [CrossRef] [PubMed]

99. Hussein, A.; Larachi, F.; Ziegler, D.; Alamdari, H. Effects of heat treatment and acid washing on properties and reactivity of charcoal. Biomass Bioenergy 2016, 90, 101-113. [CrossRef]

100. Trubetskaya, A.; Jensen, P.A.; Jensen, A.D.; Llamas, A.D.G.; Umeki, K.; Glarborg, P. Effect of fast pyrolysis conditions on biomass solid residues at high temperatures. Fuel Process. Technol. 2016, 143, 118-129. [CrossRef]

101. Bridgwater, A.V. Review of fast pyrolysis of biomass and product upgrading. Biomass Bioenergy 2012, 38, 68-94. [CrossRef]

102. Fahmi, R.; Bridgwater, A.V.; Donnison, I.S.; Yates, N.; Jones, J.M. The effect of lignin and inorganic species in biomass on pyrolysis oil yields, quality and stability. Fuel 2008, 87, 1230-1240. [CrossRef]

103. Das, P.; Ganesh, A.; Wangikar, P.P. Influence of pretreatment of deashing of sugarcane bagasse on pyrolysis products. Biomass Bioenergy 2004, 27, 445-457. [CrossRef]

104. Runge, T.; Wipperfurth, P.; Zhang, C. Improving biomass combustion quality using a liquid hot water treatment. Biofuel 2013, 4, 73-83. [CrossRef]

105. Surup, G.R. Renewable Reducing Agents for the Use in Ferroalloy Industries. Ph.D. Thesis, University of Agder, Kristiansand, Norway, 2019; p. 238.

106. Paul, M.; Seferinoğlu, M.; Ayçik, G.; Sandström, A.; Smith, M.L.; Paul, J. Acid leaching of ash and coal: Time dependence and trace element occurrences. Int. J. Miner. Process. 2006, 79, 27-41. [CrossRef]

107. Attard, T.M.; Arshadi, M.; Nilsson, C.; Budarin, V.L.; Valencia-Reyes, E.; Clark, J.H.; Hunt, A.J. Impact of supercritical extraction on solid fuel wood pellet properties and off-gassing during storage. Green Chem. 2016, 18, 2682-2690. [CrossRef]

108. Hill, K. Fats and oils as oleochemical raw materials. Eur. J. Pharm. Sci. 2000, 72, 1255-1264. [CrossRef]

109. Ruston, N.A. Commercial uses of fatty acids. J. Am. Oil Chem. Soc. 1952, 29, 495-498. [CrossRef]

110. Gill, I.; Valivety, R. Polyunsaturated fatty acids: 1. Occurrence, biological activities and applications. Trends Biotechnol. 1997, 15, 401-409. [CrossRef]

111. White, K.; Lorenz, N.; Potts, T.; Penney, W.R.; Babcock, R.; Hardison, A.; Canuel, E.A.; Hestekin, J.A. Production of biodiesel fuel from tall oil fatty acids via high temperature methanol reaction. Fuel 2011, 90, 3193-3199. [CrossRef]

112. Pereira, C.G.; Meireles, M.A.A. Economic analysis of rosemary, fennel and anise essential oils obtained by supercritical fluid extraction. Flavour Fragr. J. 2007, 22, 407-413. [CrossRef]

113. Chemat, F.; Abert Vian, M.; Cravotto, G. Green Extraction of Natural Products: Concept and Principles. Int. J. Mol. Sci. 2012, 13, 8615-8627. [CrossRef]

114. Ruiz, H.A.; Rodriquez-Jasso, R.M.; Fernandes, B.D.; Vicente, A.A.; Teixeira, J.A. Hydrothermal processing, as an alternative for upgrading agriculture residues and marine biomass according to the biorefinery concept: A review. Renew. Sustain. Energy Rev. 2013, 21, 35-51. [CrossRef]

115. Hunt, A.J.; Sin, E.H.K.; Marriott, R.; Clark, J.H. Generation, Capture, and Utilization of Industrial Carbon Dioxide. ChemSusChem 2010, 3, 306-322. [CrossRef] 
116. Sin, E.H.K.; Marriott, R.; Hunt, A.J.; Clark, J.H. Identification, quantification and Chrastil modelling of wheat straw wax extraction using supercritical carbon dioxide. C. R. Chim. 2014, 17, 293-300. [CrossRef]

117. Brunner, G. An Introduction to Fundamentals of Supercritical Fluids and the Application to Separation Processes; Springer: Berlin/Heidelberg, Germany, 1994; p. 387.

118. Brunner, G. Supercritical fluids: Technology and application to food processing. J. Food Eng. 2005, 67, 21-33. [CrossRef]

119. Arshadi, M.; Hunt, A.J.; Clark, J.H. Supercritical fluid extraction (SFE) as an effective tool in reducing auto-oxidation of dried pine sawdust for power generation. RSC Adv. 2012, 2, 1806-1809. [CrossRef]

120. Budarin, V.L.; Shuttleworth, P.S.; Dodson, J.R.; Hunt, A.J.; Lanigan, B.; Marriott, R.; Milkowski, K.J.; Wilson, A.J.; Breeden, S.W.; Fan, J.; et al. Use of green chemical technologies in an integrated biorefinery. Energy Environ. Sci. 2011, 4, 471-479. [CrossRef]

121. Smith, S.M.; Sahle Demessie, E.; Morrell, J.J.; Levien, K.L.; Ng, H. Supercritical fluid (SCF) treatment: its effect on bending strength and stiffness of ponderosa pine sapwood. Wood Fiber Sci. 1993, 25, 119-123.

122. Surup, G.R.; Hunt, A.J.; Attard, T.; Budarin, V.L.; Forsberg, F.; Arshadi, M.; Abdelsayed, V.; Shekhawat, D.; Trubetskaya, A. The effect of wood composition and supercritical $\mathrm{CO}_{2}$ extraction on charcoal production in ferroalloy industries. Energy 2020, 193, 116696. [CrossRef]

123. Singh, S.; Chakraborty, J.C.; Mondal, M.K. Torrefaction of woody biomass (Acacia nilotica): Investigation of fuel and flow properties to study its suitability as a good quality solid fuel. Renew. Energy 2020, 153, 711-724. [CrossRef]

124. Tumuluru, J.S.; Wright, C.T.; Hess, J.R.; Kenney, K.L. A review of biomass densification systems to develop uniform feedstock commodities for bioenergy application. Biofuels Bioprod. Biorefin. 2011, 5, 683-707. [CrossRef]

125. Trubetskaya, A.; Grams, J.; Leahy, J.J.; Kwapinska, M.; Monaghan, R.F.D.; Johnson, R.; Gallagher, P.; Monaghan, $\mathrm{R}$. The effect of particle size, temperature and residence time on the yields and reactivity of olive stones from torrefaction. Renew. Energy 2020, 160, 998-1011. [CrossRef]

126. Medic, C.; Darr, M.; Shah, A.; Potter, B.; Zimmermann, J. Effects of torrefaction process parameters on biomass feedstock upgrading. Fuel 2012, 91, 147-154. [CrossRef]

127. Cholewinski, M.; Kaminski, M. Torrefaction as a Means to Increase the use of Solid Biomass for Power Generation and Heating. Acta Energy 2016, 2, 60-67. [CrossRef]

128. Sangines, P.; Dominguez, M.P.; Sanchez, F.; San Miguel, G. Slow pyrolysis of olive stones in a rotary kiln: Chemical and energy characterization of solid, gas, and condensable products. J. Renew. Sustain. Energy 2015, 7, 1-13. [CrossRef]

129. Surup, G.R.; Leahy, J.J.; Timko, M.T.; Trubetskaya, A. Hydrothermal carbonization of olive wastes to produce renewable, binder-free pellets for use as metallurgical reducing agents. Renew. Energy 2020, 155, 347-357. [CrossRef]

130. Hamid, M.F.; Idroas, M.Y.; Ishak, M.Z.; Zainal Alauddin, Z.A.; Miskam, M.A.; Abdullah, M.K. An Experimental Study of Briquetting Process of Torrefied Rubber Seed Kernel and Palm Oil Shell. BioMed Res. Int. 2016, 1, 1-11. [CrossRef] [PubMed]

131. Funke, A.; Ziegler, F. Heat of reaction measurements for hydrothermal carbonization of biomass. Bioresour. Technol. 2011, 102, 7595-7598. [CrossRef]

132. Saha, P.; McGaughy, K.; Hasan, R.; Reza, M.T. Pyrolysis and carbon dioxide gasification kinetics of hydrochar produced from cow manure. Environ. Prog. Sustain. Energy 2018, 102, 7595-7598. [CrossRef]

133. Reza, M.T.; Uddin, M.H.; Lynam, J.; Hoekman, S.K.; Coronella, C. Hydrothermal carbonization of loblolly pine: Reaction chemistry and water balance. Biomass Convers. Biorefin. 2014, 4, 311-321. [CrossRef]

134. Ahmad, F.; Silva, E.L.; Varesche, M.B.A. Hydrothermal processing of biomass for anaerobic digestion-A review. Renew. Sustain. Energy Rev. 2018, 98, 108-124. [CrossRef]

135. He, C.; Tang, C.; Li, C.; Yuan, J.; Tran, K.Q.; Bach, Q.V.; Qiu, R.; Yang, Y. Wet torrefaction of biomass for high quality solid fuel production: A review. Renew. Sustain. Energy Rev. 2018, 91, 259-271. [CrossRef]

136. Delahaye, L.; Hobson, J.T.; Rando, M.P.; Sweeney, B.; Brown, A.B.; Tompsett, G.A.; Ates, A.; Deskins, N.A.; Timko, M.T. Experimental and Computational Evaluation of Heavy Metal Cation Adsorption for Molecular Design of Hydrothermal Char. Energies 2020, 13, 4203. [CrossRef] 
137. Volpe, M.; Fiori, L. From olive waste to solid biofuel through hydrothermal carbonization: The role of temperature and solid load on secondary char formation and hydrochar energy properties. J. Anal. Appl. Pyrolysis 2017, 124, 63-72. [CrossRef]

138. Lucian, M.; Fiori, L. Hydrothermal carbonization of waste biomass: Process design, modeling, energy efficiency and cost analysis. Energies 2017, 10, 211. [CrossRef]

139. Mandova, H.; Leduc, S.; Wang, C.; Wetterlund, E.; Patrizio, P.; Gale, W.; Kraxner, F. Possibilities for $\mathrm{CO}_{2}$ emission reduction using biomass in European integrated steel plants. Biomass Bioenergy 2018, 115, 231-243. [CrossRef]

140. Shang, L.; Nielsen, N.P.K.; Stelte, W.; Dahl, J.; Ahrendfeldt, J.; Holm, J.K.; Arnavat, M.P.; Bach, L.S. Lab and Bench-Scale Pelletization of Torrefied Wood Chips-Process Optimization and Pellet Quality. Bioenergy Res. 2014, 7, 87-94. [CrossRef]

141. Dutta, S.K. Iron ore-coal composite pellets/briquettes as new feed material for iron and steelmaking. Mater. Sci. Eng. Int. J. 2017, 1, 10-13.

142. Surup, G.R.; Nielsen, H.K.; Großarth, M.; Deike, R.; Van den Bulcke, J.; Kibleur, P.; Müller, M.; Ziegner, M.; Yazhenskikh, E.; Beloshapkin, S.; et al. Effect of operating conditions and feedstock composition on the properties of manganese oxide or quartz charcoal pellets for the use in ferroalloy industries. Energy 2020, 193, 116736. [CrossRef]

143. Riva, L. Production and Application of Sustainable Metallurgical Biochar Pellets. Ph.D. Thesis, University of Agder, Kristiansand, Norway, 2020; p. 284.

144. Nascimento, R.C.; Mourao, M.B.; Capocchi, J.D.T. Reduction-swelling behaviour of pellets bearing iron ore and charcoal. Can. Metall. Q. 1998, 37, 441-448. [CrossRef]

145. Yoshikoshi, H.; Takeuchi, O.; Miyashita, T.; Kuwana, T.; Kishikawa, K. Development of Composite Cold Pellet for Silico-Manganese Production. Trans. ISIJ 1984, 24, 492-497. [CrossRef]

146. Tangstad, M.; Leroy, D.; Ringdalen, E. Behaviour of agglomerates in ferromanganese production. In Proceedings of the INFACON XII, Hensinki, Finland, 6-10 June 2010; pp. 457-466.

147. Abedi, A.; Cheng, H.; Dalai, A.K. Effects of natural additives on the properties of sawdust fuel pellets. Energy Fuels 2018, 32, 1863-1873. [CrossRef]

148. Bach, Q.V.; Skreiberg, O. Upgrading biomass fuels via wet torrefaction: A review and comparison with dry torrefaction. Renew. Sustain. Energy Rev. 2016, 54, 665-677. [CrossRef]

149. Wnukowski, M.; Owczarek, P.; Niedzwiecki, L. Wet torrefaction of miscanthus-Characterization of hydrochars in view of handling, storage and combustion properties. J. Ecol. Eng. 2015, 16, 161-167. [CrossRef]

150. Riva, L.; Surup, G.R.; Buø, T.V.; Nielsen, H.K. A study of densified biochar as carbon source in the silicon and ferrosilicon production. Energy 2019, 181, 985-996. [CrossRef]

151. Liu, Z.; Quek, A.; Balasubramanian, R. Preparation and characterization of fuel pellets from woody biomass, agro-residues and their corresponding hydrochars. Appl. Energy 2014, 113, 1315-1322. [CrossRef]

152. Antal, M.J.; Mok, W.S.L.; Varhegyi, G.; Szekely, T. Review of methods for improving the yield of charcoal from biomass. Energy Fuels 1990, 4, 221-225. [CrossRef]

153. Antal, M.J.; Croiset, E.; Dai, X.; DeAlmeida, C.; Mok, W.S.L.; Norberg, N.; Richard, J.-R.; Majthoub, A. High-Yield Biomass Charcoal. Energy Fuels 1996, 10, 652-658. [CrossRef]

154. Lehmann, J.; Joseph, S. Biochar for Environmental Management: Science, Technology and Implementation; Routledge: Abingdon, UK, 2015.

155. Weber, K.; Quicker, P. Properties of biochar. Fuel 2018, 217, 240-261. [CrossRef]

156. Kan, T.; Strezov, V.; Evans, T.J. Lignocellulosic biomass pyrolysis: A review of product properties and effects of pyrolysis parameters. Renew. Sustain. Energy Rev. 2016, 57, 1126-1140. [CrossRef]

157. Wang, L.; Trninic, M.; Skreiberg, Ø.; Grønli, M.; Considine, R.; Antal, M.J. Is elevated pressure required to achieve a high fixed-carbon yield of charcoal from biomass? Part 1: Roundrobin results for three different corncob materials. Energy Fuels 2011, 25, 3251-3265. [CrossRef]

158. Wang, L.; Skreiberg, Ø.; Grønli, M.; Specht, G.P.; Antal, M.J. Is elevated pressure required to achieve fixed-carbon yield of charcoal from biomass? Part 2. The importance of particle size. Energy Fuels 2013, 27, 2146-2156. [CrossRef] 
159. Rousset, P.; Figueiredo, C.; De Souza, M.; Quirino, W. Pressure effect on the quality of eucalyptus wood charcoal for the steel industry: A statistical analysis approach. Fuel Process. Technol. 2011, 92, 1890-1897. [CrossRef]

160. De Oliveira Vilela, A.; Lora, E.S.; Quintero, Q.R.; Vicintin, R.A.; da Silva e Souza, T.P. A new technology for the combined production of charcoal and electricity through cogeneration. Biomass Bioenergy 2014, 69, 222-240. [CrossRef]

161. Kajina, W.; Junpen, A.; Garivait, S.; Kamnoet, O.; Keeratiisariyakul, P.; Rousset, P. Charcoal production processes: An overview. J. Sustain. Energy Environ. 2019, 10, 19-25.

162. Amen-Chen, C.; Pakdel, H.; Roy, C. Separation of phenols from Eucalyptus wood tar. Biomass Bioenergy 1997, 13, 25-37. [CrossRef]

163. Teplitz-Sembitzky, W. The Malawi Charcoal Project-Experiences and Lessons; Industry and Energy Department Working Paper, Energy Series Paper No. 20; The World Bank: Washington, DC, USA, 1990.

164. Trninić, M.; Jovović, A.; Stojiljković, D. A steady state model of agricultural waste pyrolysis: A mini review. Waste Manag. Res. 2016, 34, 851-865. [CrossRef]

165. Lam, K.-L.; Lee, C.-W.; Hui, C.-W. Multi-stage Waste Tyre Pyrolysis: An Optimisation Approach. Chem. Eng. Trans. 2010, 21, 853-858.

166. Oyedun, A.O.; Lam, K.L.; Hui, C.W. Charcoal Production via Multistage Pyrolysis. Chin. J. Chem. Eng. 2012, 20, 455-460. [CrossRef]

167. Cheung, K.-Y.; Lee, K.-L.; Lam, K.-L.; Chan, T.-Y.; Lee, C.-W.; Hui, C.-W. Operation strategy for multi-stage pyrolysis. J. Anal. Appl. Pyrolysis 2011, 91, 165-182. [CrossRef]

168. Dahmen, N.; Dinjus, E.; Kolb, T.; Arnold, U.; Leibold, H.; Stahl, R. State of the Art of the Bioliq ${ }^{\circledR}$ Process for Synthetic Biofuels Production. Environ. Prog. Sustain. 2012, 31, 176-181. [CrossRef]

169. Vehviläinen, J. Challenges in rendering co-rich gas from submerged arc furnaces sufficiently clean for co-generation application. In Proceedings of the International Ferro-Alloys Congress XIII, Almaty, Kazakhstan, 9-13 June 2013; pp. 1009-1014.

170. Kero, I.T.; Eidem, P.A.; Ma, Y.; Indresand, H.; Aarhaug, T.A.; Grådahl, S. Airborne Emissions from Mn Ferroalloy Production. JOM 2019, 71, 349-365. [CrossRef]

171. Trubetskaya, A.; Timko, M.T.; Umeki, K. Prediction of fast pyrolysis products yields using lignocellulosic compounds and ash contents. Appl. Energy 2020, 257, 113897. [CrossRef]

172. Funke, A.; Demus, T.; Willms, T.; Schenke, L.; Echterhof, T.; Niebel, A.; Pfeifer, H.; Dahmen, N. Application of fast pyrolysis char in an electric arc furnace. Fuel Process. Technol. 2018, 174, 61-68. [CrossRef]

173. Septien, S.; Valin, S.; Dupont, C.; Peyrot, M.; Salvador, S. Effect of particle size and temperature on woody biomass fast pyrolysis at high temperature $\left(1000-1400^{\circ} \mathrm{C}\right)$. Fuel 2012, 97, 202-210. [CrossRef]

174. Liaw, S.B.; Wu, H. A New Method for Direct Determination of Char Yield during Solid Fuel Pyrolysis in Drop-Tube Furnace at High Temperature and Its Comparison with Ash Tracer Method. Energy Fuels 2019, 33, 1509-1517. [CrossRef]

175. Zhang, Y.; Kajitani, S.; Ashizawa, M.; Oki, Y. Tar destruction and coke formation during rapid pyrolysis and gasification of biomass in a drop-tube furnace. Fuel 2010, 89, 302-309. [CrossRef]

176. Trubetskaya, A.; Souihi, N.; Umeki, K. Categorization of tars from fast pyrolysis of pure lignocellulosic compounds at high temperature. Renew. Energy 2019, 141, 751-759. [CrossRef]

177. Radlein, D.; Quignard, A. A Short Historical Review of Fast Pyrolysis of Biomass. Oil Gas Sci. Technol. 2013, 68, 765-783. [CrossRef]

178. Pires, A.P.P.; Arauzo, J.; Fonts, I.; Domine, M.E.; Arroyo, A.F.; Garcia-Perez, M.E.; Montoya, J.; Chejne, F.; Pfromm, P.; Garcia-Perez, M. Challenges and Opportunities for Bio-oil Refining: A Review. Energy Fuels 2019, 33, 4683-4720. [CrossRef]

179. Mostafazadeh, A.K.; Solomatnikova, O.; Drogui, P.; Tyagi, R.D. A review of recent research and developments in fast pyrolysis and bio-oil upgrading. Biomass Convers. Biorefin. 2018, 8, 739-773. [CrossRef]

180. Riva, L.; Nielsen, H.K.; Skreiberg, Ø.; Wang, L.; Bartocci, P.; Barbanera, M.; Bidini, G.; Fantozzi, F. Analysis of optimal temperature, pressure and binder quantity for the production of biocarbon pellet to be used as a substitute for coke. Appl. Energy 2019, 256, 113933. [CrossRef]

181. Elkasabi, Y.; Boateng, A.A.; Jackson, M.A. Upgrading of bio-oil distillation bottoms into biorenewable calcined coke. Biomass Bioenergy 2015, 81, 415-423. [CrossRef] 
182. Pennise, D.M.; Smith, K.R.; Kithinji, J.P.; Rezende, M.E.; Raad, T.J.; Zhang, J.; Fan, C. Emissions of greenhouse gases and other airborne pollutants from charcoal making in Kenya and Brazil. J. Geophys. Res. 2001, 106, 143-155. [CrossRef]

183. Simoneit, B.R.T.; Rogge, W.F.; Lang, Q.; Jaffé, R. Molecular characterization of smoke from campfire burning of pine wood (textitPinus elliottii). Chemosph. Glob. Chang. Sci. 2000, 2, 107-122. [CrossRef]

184. Oanh, N.T.K.; Nghiem, L.H.; Phyu, Y.L. Emission of Polycyclic Aromatic Hydrocarbons, Toxicity, and Mutagenicity from Domestic Cooking Using Sawdust Briquettes, Wood, and Kerosene. Environ. Sci. Technol. 2002, 36, 833-839. [CrossRef] [PubMed]

185. Andersson, J.T.; Achten, C. Time to Say Goodbye to the 16 EPA PAHs? Toward an Up-to-Date Use of PACs for Environmental Purposes. Polycyl. Aromat. Compd. 2015, 35, 330-354. [CrossRef] [PubMed]

186. National Institute for Occupational Safety and Health (NIOSH). Criteria for a Recommended Standard: Occupational Exposure to Carbon Black; DHHS (NIOSH) Publication Number 78-204; NIOSH: Washington, DC, USA, 1978.

187. Chen, H.; Si, Y.; Chen, Y.; Yang, H.; Chen, D.; Chen, W. NO $\mathrm{NO}_{x}$ precursors from biomass pyrolysis: Distribution of amino acids in biomass and Tar-N during devolatilization using model compounds. Fuel 2017, 187, 367-375. [CrossRef]

188. Cheah, S.; Malone, S.C.; Feik, C.J. Speciation of Sulfur in Biochar Produced from Pyrolysis and Gasification of Oak and Corn Stover. Environ. Sci. Technol. 2014, 48, 8474-8480. [CrossRef]

189. Van Dam, J. The Charcoal Transition: Greening the Charcoal Value Chain to Mitigate Climate Change and Improve Local Livelihoods; FAO: Rome, Italy, 2017.

190. Brocksiepe, H.-G. Charcoal. In Ullmann's Encyclopedia of Industrial Chemistry; Wiley-VCH: Weinheim, Germany, 2012; Volume 8, pp. 93-98.

191. Sparrevik, M.; Adam, C.; Martinsen, V.; Jubaedah, V.; Cornelissen, G. Emissions of gases and particles from charcoal/biochar production in rural areas using medium.sized traditional and improved "retort" kilns. Biomass Bioenergy 2015, 72, 65-73. [CrossRef]

192. Cornelissen, G.; Pandit, N.R.; Taylor, P.; Pandit, B.H.; Sparrevik, M.; Schmidt, H.P. Emissions and Char Quality of Flame-Curtain "Kon Tiki" Kilns for Farmer-Scale Charcoal/Biochar Production. PLoS ONE 2016, 11, e0154617. [CrossRef]

193. Chen, J.; Li, S.; Liang, C.; Xu, Q.; Li, Y.; Fuhrmann, J.J. Response of microbial community structure and function to short-term biochar amendment in an intensively managed bamboo (Phyllostachys praecox). Sci. Total Environ. 2017, 574, 24-33. [CrossRef]

194. Zhu, W.; Song, W.; Lin, W. Catalytic gasification of char from co-pyrolysis of coal and biomass. Fuel Process. Technol. 2008, 89, 890-896. [CrossRef]

195. Demirbaş, A. Sustainable Charcoal Production and Charcoal Briquetting. Energy Sources Part A 2009, 31, 1694-1699. [CrossRef]

196. Akowuah, J.O.; Kemausuor, F.; Mitchual, S.J. Physico-chemical characteristics and market potential of sawdust charcoal briquette. IJEE 2012, 3,1-6. [CrossRef]

197. Li, F.; Tangstad, M.; Solheim, I. Quartz and carbon black pellets for silicon production. In Proceedings of the INFACON XIV, Kiev, Ukraine, 31 May-4 June 2015; pp. 390-401.

198. Hardianto, T.; Pambudi, F.F.; Irhamna, A.R. A study on lignin characteristic as internal binder in hot briquetting process of organic municipal solid waste. In Proceedings of the AIP Conference Proceedings 1984, Bali, Indonesia, 17-19 November 2017; p. 030013.

199. Lumadue, M.R.; Cannon, F.; Brown, N.R. Lignin as both fuel and fusing binder in briquetted anthracite fines for foundry coke substitute. Fuel 2012, 97, 869-875. [CrossRef]

200. Surup, G.R.; Heidelmann, M.; Nielsen, H.K.; Trubetskaya, A. Characterization and reactivity of charcoal from high temperature pyrolysis $\left(800-1600{ }^{\circ} \mathrm{C}\right)$. Fuel 2019, 235, 1544-1554. [CrossRef]

201. Surup, G.R.; Pedersen, T.A.; Chaldien, A.; Beukes, J.P.; Tangstad, M. Electrical Resistivity of Carbonaceous Bed Material at High Temperature. Processes 2020, 8, 933. [CrossRef]

202. Chen, J.; Zhou, F.; Si, T.; Zhou, J.; Cen, K. Mechanical strength and combustion properties of biomass pellets prepared with coal tar residue as a binder. Fuel Process. Technol. 2018, 179, 229-237. [CrossRef]

203. Coulon, F.; Orsi, R.; Turner, C.; Walton, C.; Daly, P.; Pollard, S.J. Understanding the fate and transport of petroleum hydrocarbons from coal tar within gasholders. Environ. Int. 2009, 35, 248-252. [CrossRef] 
204. Wang, X.; Shen, J.; Niu, Y.; Sheng, Q.; Liu, G.; Wang, Y. Solvent extracting coal gasification tar residue and the extracts characterization. J. Clean. Prod. 2016, 133, 965-970. [CrossRef]

205. Craven, J.M.; Swithenbank, J.; Sharifi, V.N.; Peralta-Solorio, D.; Kelsall, G.; Sage, P. Hydrophobic coatings for moisture stable wood pellets. Biomass Bioenergy 2015, 80, 278-285. [CrossRef]

206. Asadullah, M.; Zhang, S.; Li, C.-Z. Evaluation of structural features of chars from pyrolysis of biomass of different particle sizes. Fuel Process. Technol. 2010, 91, 877-881. [CrossRef]

207. Ronsse, F. Commercial biochar production and its certification. Presented at the Interreg Conference, Groningen, The Netherlands, 10 December 2013.

208. Quicker, P.; Weber, K. Biokohle-Herstellung, Eigenschaften und Verwendung von Biomassekarbonisaten; Springer Vieweg: Medford, MA, USA, 2016.

209. Antal, M.J.; Allen, S.G.; Dai, X.; Shimizu, B.; Tam, M.S.; Grønli, M. Attainment of the Theoretical Yield of Carbon from Biomass. Ind. Eng. Chem. Res. 2000, 39, 4024-4031. [CrossRef]

210. Amini, E.; Safdari, M.-S.; DeYoung, J.T.; Weise, D.R.; Fletcher, T.H. Characterization of pyrolysis products from slow pyrolysis of live and dead vegetation native to the southern United States. Fuel 2019, 235, 1475-1491. [CrossRef]

211. Wesenbeeck, S.V.; Higashi, C.; Legarra, M.; Wang, L.; Antal, M.J. Biomass Pyrolysis in Sealed Vessels. Fixed-Carbon Yields from Avicel Cellulose That Realize the Theoretical Limit. Energy Fuels 2016, 30, 480-491. [CrossRef]

212. Soto Veiga, J.P.; Romanelli, T.L. Mitigation of greenhouse gas emissions using exergy. J. Clean. Prod. 2020, 260, 121092. [CrossRef]

213. Yoshida, T.; Turn, S.Q.; Yost, R.S.; Antal, M.J. Banagrass vs Eucalyptus Wood as Feedstocks for Metallurgical Biocarbon Production. Ind. Eng. Chem. Res. 2008, 47, 9882-9888. [CrossRef]

214. Kimura, L.M.; Santos, L.C.; Vieira, P.F.; Parreira, P.M.; Henrique, H.M. Biomass Pyrolysis: Use of Some Agricultural Wastes for Alternative Fuel Production. In Proceedings of the Seventh International Latin American Conference on Powder Technology, Atibaia, Brazil, 8-10 November 2009; pp. 274-279.

215. Islam, M.N.; Ali, M.H.; Ahman, I. Fixed bed slow pyrolysis of biomass solid waste for bio-char. IOP Conf. Ser. Mater. Sci. Eng. 2017, 206, 012014. [CrossRef]

216. Czajczyńska, D.; Anguilano, L.; Ghazal, H.; Krzyżyńska, R.; Reynolds, A.J.; Spencer, N.; Jouhara, H. Potential of pyrolysis processes in the waste management sector. Therm. Sci. Eng. Prog. 2017, 3, 171-197. [CrossRef]

217. Roy, P.; Dias, G. Prospects for pyrolysis technologies in the bioenergy sector: A review. Renew. Sustain. Energy Rev. 2017, 77, 59-69. [CrossRef]

218. Antal, M.J.; Mochidzuki, K.; Paredes, L.S. Flash Carbonization of Biomass. Ind. Eng. Chem. Res. 2003, 42, 3690-3699. [CrossRef]

219. Ringer, M.; Putsche, V.; Scahill, J. Large-Scale Pyrolysis Oil Production: A Technology Assessment and Economic Analysis; Report Number: NREL/TP-510-37779; National Renewable Energy Laboratory: Golden, CO, USA, 2006.

220. Tintner, J.; Preimesberger, C.; Pfeifer, C.; Theiner, J.; Ottner, F.; Wriessnig, K.; Puchberger, M.; Smidt, E. Pyrolysis profile of a rectangular kiln-Natural scientific investigation of a traditional charcoal production process. J. Anal. Appl. Pyrolysis 2020, 146, 104757. [CrossRef]

221. Chidumayo, E.N. Is charcoal production in Brachystegia-Julbernardia woodlands of Zambia sustainable? Biomass Bioenergy 2019, 125, 1-7. [CrossRef]

222. Duarte, S.J.; Lin, J.; Alviso, D.; Rolón, J.C. Effect of Temperature and Particle Size on the Yield of Bio-oil, Produced from Conventional Coconut Core Pyrolysis. Int. J. Chem. Eng. Appl. 2016, 7, 102-108. [CrossRef]

223. Neves, D.; Matos, A.; Tarelho, L.; Thunman, H.; Larsson, A.; Seemann, M. Volatile gases from biomass pyrolysis under conditions relevant for fluidized bed gasifiers. J. Anal. Appl. Pyrolysis 2017, 127, 57-67. [CrossRef]

224. Chen, H. Lignocellulose Biorefinery Conversion Engineering; Woodhead Publishing: Cambridge, UK, 2015; pp. 87-124.

225. Bridgwater, T.; Carson, P.; Coulson, M. A comparison of fast and slow pyrolysis liquids from mallee. Int. J. Glob. Energy 2007, 27, 204-216. [CrossRef]

226. Grønli, M. Industrial Production of Charcoal; SINTEF Energy Research: Trondheim, Norway, 1999.

227. Scholze, B.; Meier, D. Characterization of the water-insoluble fraction from pyrolysis oil (pyrolytic lignin). Part I. PY-GC/MS, FTIR, and functional groups. J. Anal. Appl. Pyrolysis 2001, 60, 41-54. [CrossRef] 
228. Mullen, C.A.; Boateng, A.A. Chemical Composition of Bio-oils Produced by Fast Pyrolysis of Two Energy Crops. Energy Fuels 2008, 22, 2104-2109. [CrossRef]

229. Meng, J.; Moore, A.; Tilotta, D.C.; Kelley, S.S.; Adhikar, S.; Park, S. Thermal and Storage Stability of Bio-Oil from Pyrolysis of Torrefied Wood. Energy Fuels 2015, 29, 5117-5126. [CrossRef]

230. Diebold, J.P. A Review of the Chemical and Physical Mechanisms of the Storage Stability of Fast Pyrolysis Bio-Oils; Report N. NREL/SR-570-27613; Contract No.: DE-AC36-99-GO10337; National Renewable Energy Laboratory: Golden, CO, USA, 1999.

231. Lawal, A.T. Polycyclic aromatic hydrocarbons. A review. Cogent Environ. Sci. 2017, 31, 1339841. [CrossRef]

232. Chen, D.; Zhou, J.; Zhang, Q.; Zhu, X. Evaluation methods and research progresses in bio-oil storage stability. Renew. Sustain. Energy Rev. 2014, 40, 69-79. [CrossRef]

233. Sarkar, J.K.; Wang, Q. Different Pyrolysis Process Conditions of South Asian Waste Coconut Shell and Characterization of Gas, Bio-Char, and Bio-Oil. Energies 2020, 13, 1970. [CrossRef]

234. Crombie, K.; Mašek, O. Investigating the potential for a self-sustaining slow pyrolysis system under varying operating conditions. Bioresour. Technol. 2014, 162, 148-156. [CrossRef]

235. Panwara, N.L.; Kothari, R.; Tyagi, V.V. Thermo chemical conversion of biomass - Eco friendly energy routes. Renew. Sustain. Energy Rev. 2012, 16, 1801-1816. [CrossRef]

236. Jin, W.; Pastor-Pérez, L.; Yu, J.; Odriozola, J.A.; Gu, S.; Reina, T.R. Cost-effective routes for catalytic biomass upgrading. Curr. Opin. Green Sustain. Chem. 2020, 23, 1-9. [CrossRef]

237. Zheng, J.-L.; Zhu, Y.-H.; Zhu, M.-Q.; Kang, K.; Sun, R.-C. A review of gasification of bio-oil for gas production. Sustain. Energy Fuels 2019, 7, 1600-1622. [CrossRef]

238. Dahmen, N.; Henrich, E.; Dinjus, E.; Weirich, F. The bioliq ${ }^{\circledR}$ bioslurry gasification process for the production of biosynfuels, organic chemicals, and energy. Energy Sustain. Soc. 2012, 2, 1-44. [CrossRef]

239. Subramanian, M.; Harman, C.N. Problems and Prospects of carbonaceous reducing agents in ferro alloys production. In Proceedings of the Seminar on Problems and Prospects of Ferro-Alloy Industry in India, Jamshedpur, India, 24-26 October 1983; pp. 133-140.

240. Lindstad, T.; Olsen, S.; Tranell, G.; Færden, T.; Lubetsky, J. Greenhouse gas emissions from ferroalloy production. In Proceedings of the INFACON XI, New Delhi, India, 18-21 February 2007; pp. 457-466.

241. Díez, M.A.; Alvarez, R.; Barriocanal, C. Coal for metallurgical coke production: Predictions of coke quality and future requirements for cokemaking. Int. J. Coal Geol. 2002, 50, 389-412. [CrossRef]

242. Valia, H.S. Coke Production for Blast Furnace Ironmaking; Ispat Inland Inc.: Chicago, IN, USA, 2015.

243. Babich, A.; Senk, D. Chapter 12-Coal use in iron and steel metallurgy. In The Coal Handbook: Towards Cleaner Production; Osborne, D., Ed.; Woodhead Publishing Series in Energy; Woodhead Publishing: Cambridge, UK, 2013; Volume 2, pp. 267-311.

244. United States International Trade Commission. Metallurgical Coke: Baseline Analysis of the U.S. Industry and Imports: [Investigation No. 332-342]; USITC Publication; U.S. International Trade Commission: Washington, DC, USA, 1994.

245. Schobert, H.; Schobert, N. Comparative Carbon Footprints of Metallurgical Coke and Anthracite for Blast Furnace and Electric Arc Furnace Use. 2015. Available online: http:/ / www.blaschakcoal.com/wp-content/ uploads/Carbon-Footprint-Archival-Report-v-4-September-2015.pdf (accessed on 17 September 2020).

246. Eidem, P.A.; Runde, M.; Tangstad, M.; Bakken, J.A.; Zhou, Z.Y.; Yu, A.B. Effect of Contact Resistance on Bulk Resistivity of Dry Coke Beds. Metall. Mater. Trans. B 2009, 40B, 388-396. [CrossRef]

247. Khanna, R.; Li, K.; Wang, Z.; Sun, M.; Zhang, J.; Mukherjee, P.S. Biochars in iron and steel industries. In Char and Carbon Materials Derived from Biomass: Production, Characterization and Applications; Elsevier: Amsterdam, The Netherlands, 2019; pp. 429-446.

248. Yunos, N.F.M. Recycling Agricultural Waste from Palm Shells during Electric Arc Furnace Steelmaking. Energy Fuels 2011, 26, 278-286. [CrossRef]

249. Wang, C.; Mellin, P.; Lövgren, J.; Nilsson, L.; Yang, W.; Salam, H.; Hultgren, A.; Larsson, M. Biomass as blast furnace injectant-Considering availability pretreatment and deployment in the Swedish steel industry. Energy Convers. Manag. 2015, 102, 217-226. [CrossRef]

250. Júnior, A.F.D.; de Oliveira, R.N.; Deglise, X.; de Souzam, N.D.; Brito, J.O. Infrared spectroscopy analysis on charcoal generated by the pyrolysis of Corymbia. citriodora wood. Matéria (Rio de Janeiro) 2019, 24, 1-7.

251. Labbé, N.; Harper, D.; Rials, T. Chemical Structure of Wood Charcoal by Infrared Spectroscopy and Multivariate Analysis. J. Agric. Food Chem. 2006, 54, 3492-3497. [CrossRef] 
252. Chen, Z.; Ma, W.; Wu, J.; Wei, K.; Lei, Y.; Ly, G. A Study of the Performance of Submerged Arc Furnace Smelting of Industrial Silicon. Silicon 2018, 10, 1121-1127. [CrossRef]

253. Sahajwalla, V.; Dubikova, M.; Khanna, R. Reductant characterisation and selection: Implications for ferroalloys processing. In Proceedings of the INFACON X, Cape Town, South Africa, 1-4 February 2004; pp. 351-362.

254. Chen, Y.; Aanjaneya, K.; Atreya, A. A study to investigate pyrolysis of wood particles of various shapes and sizes. Fire Saf. J. 2017, 91, 820-827. [CrossRef]

255. Kenney, W.A.; Sennerby-Forsse, L.; Layton, P. A Review of Biomass Quality Research Relevant to the Use of Poplar and Willow for Energy Conversion. Biomass 1990, 21, 163-188. [CrossRef]

256. Plötze, M.; Niemz, P. Porosity and pore size distribution of different wood types as determined by mercury intrusion porosimetry. Eur. J. Wood Wood Prod. 2011, 69, 649-657. [CrossRef]

257. Hu, Q.; Yang, H.; Yao, D.; Zhu, D.; Wang, X.; Shao, J.; Chen, H. The densification of bio-char: Effect of pyrolysis temperature on the qualities of pellets. Bioresource 2016, 200, 521-527. [CrossRef]

258. Brewer, C.E.; Chuang, V.J.; Masiello, C.A.; Gonnermann, H.; Gao, X.; Dugan, B.; Driver, L.E.; Panzacchi, P.; Zygourakis, K.; Davies, C.A. New approaches to measuring biochar density and porosity. Biomass Bioenergy 2014, 66, 176-185. [CrossRef]

259. Somerville, M.; Jahanshahi, S. The effect of temperature and compression during pyrolysis on the density of charcoal made from Australian eucalypt wood. Renew. Energy 2015, 80, 471-478. [CrossRef]

260. Florentino-Madiedo, L.; Díaz-Faes, E.; Barriocanal, C. Mechanical strength of bio-coke from briquettes. Renew. Energy 2020, 146, 1717-1724. [CrossRef]

261. Sato, H.; Patrick, J.W.; Walker, A. Effect of coal properties and porous structure on tensile strength of metallurgical coke. Fuel 1998, 77, 1203-1208. [CrossRef]

262. Montiano, M.G.; Díaz-Faes, E.; Barriocanal, C.; Alvarez, R. Influence of biomass on metallurgical coke quality. Fuel 2014, 116, 175-182. [CrossRef]

263. Newalkar, G.; Iisa, K.; D'Amico, A.D.; Sievers, C.; Agrawal, P. Effect of Temperature, Pressure, and Residence Time on Pyrolysis of Pine in an Entrained Flow Reactor. Energy Fuels 2014, 28, 5144-5157. [CrossRef]

264. Lee, Y.; Park, J.; Ryu, C.; Gang, K.S.; Yang, W.; Park, Y.; Jung, J.; Hyun, S. Comparison of biochar properties from biomass residues produced by slow pyrolysis at $500^{\circ} \mathrm{C}$. Bioresour. Technol. 2013, 148, 196-201. [CrossRef]

265. Yan, M.; Zhang, S.; Wibowo, H.; Grisdanurak, N.; Cai, Y.; Zhou, X.; Kanchanatip, E.; Antoni. Biochar and pyrolytic gas properties from pyrolysis of simulated municipal solid waste (SMSW) under pyrolytic gas atmosphere. Waste Dispos. Sustain. Energy 2020, 2, 37-46. [CrossRef]

266. Ronsse, F.; van Hecke, S.; Dickinson, D.; Prins, W. Production and characterization of slow pyrolysis biochar: influence of feedstock type and pyrolysis conditions. GCB Bioenergy 2013, 5, 104-115. [CrossRef]

267. Wang, L.; Hovd, B.; Bui, H.-H.; Valderhaug, A.; Buø, T.V.; Birkeland, R.G.; Skreiberg, Ø.; Tran, K.-Q. CO 2 Reactivity Assessment of Woody Biomass Biocarbons for Metallurgical Purposes. Chem. Eng. Trans. 2016, 50, 55-60.

268. Mukherjee, A.; Zimmerman, A.R.; Harris, W. Surface chemistry variations among a series of laboratory-produced biochars. Geoderma 2011, 163, 247-255. [CrossRef]

269. Forest Products Laboratory. Charcoal Production, Marketing, and Use; Technical Report No. 2213; US Department of Agriculture: Madison, WI, USA, 1961.

270. Foley, G. Charcoal Making in Developing Countries; Energy Information Programme Technical Report No. 5; Earthscan: London, UK, 1986.

271. Food and Agriculture Organization of the United Nations. Simple Technologies for Charcoal Making; FAO Forestry Paper 41, Bd 4; Food and Agriculture Organization of the United Nations: Rome, Italy, 1987.

272. Mizuno, S.; Ida, T.; Fuchihata, M.; Sanchez, E.; Yoshikuni, K. Formation characteristics of bio-coke produced from waste agricultural biomass. In Proceedings of the ASME 2015 InterPACK2015, San Francisco, CA, USA, 6-9 July 2015; pp. 1-5.

273. Byrne, C.E.; Nagle, D.C. Carbonization of wood for advanced materials applications. Carbon 1997, 35, 259-266. [CrossRef]

274. Riva, L.; Cardarelli, A.; Andersen, G.J.; Buø, T.V.; Barbanera, M.; Bartocci, P.; Fantozzi, F.; Nielsen, H.K. On the self-heating behavior of upgraded biochar pellets blended with pyrolysis oil: Effects of process parameters. Fuel 2020, 278, 118395. [CrossRef] 
275. Safana, A.A.; Abdullah, N.; Sulaiman, F. Bio-char and bio-oil mixtures derived from the pyrolysis of mesocarp fibre for for briquettes production. J. Oil Palm Res. 2018, 30, 130-140.

276. Huang, H.; Fox, J.T.; Cannon, F.S.; Komarneni, S. In situ growth of silicon carbide nanowires from anthracite surfaces. Ceram Int. 2011, 37, 1063-1072. [CrossRef]

277. Wang, N.; Low, M.J.D. Spectroscopic studies of carbons. XV. The pyrolysis of a lignin. Mater. Chem. Phys. 1990, 26, 67-80. [CrossRef]

278. Dijs, H.; Smith, D. Factors affecting the resistivity and reactivity of carbonaceous reducing agents for the electric-smelting industry. J. S. Afr. Inst. Min. Metall. 1980, 80, 286-296.

279. Eidem, P.A.; Tangstad, M.; Bakken, J.A. Measurement of material resistivity and contact resistance of metallurgical coke. In Proceedings of the INFACON XI, New Delhi, India, 18-21 February 2007; pp. 561-571.

280. Eidem, P.A.; Tangstad, M.; Bakken, J.A.; Ishak, R. Influence of coke particle size on the electrical resistivity of coke beds. In Proceedings of the INFACON XII, Hensinki, Finland, 6-9 June 2010; pp. 349-358.

281. Feng, B.; Bhatia, S.K.; Barry, J.C. Structural ordering of coal char during heat treatment and its impact on reactivity. Carbon 2002, 40, 481-496. [CrossRef]

282. Tangstad, M.; Beukes, J.P.; Steenkamp, J.; Ringdalen, E. 14-Coal-based reducing agents in ferroalloys and silicon production. In New Trends in Coal Conversion Combustion, Gasification, Emissions, and Coking; Woodhead Publishing: Cambridge, UK, 2019; pp. 405-438.

283. Adinaveen, T.; Vijaya, J.J.; Kennedy, L. Comparative Study of Electrical Conductivity on Activated Carbons Prepared from Various Cellulose Materials. Arab. J. Sci. Eng. 2014, 41, 55-65. [CrossRef]

284. Behazin, E.; Ogunsona, E.; Rodriguez-Uribe, A.; Mohanty, A.; Misra, M.; Anyia, A.O. Mechanical, Chemical, and Physical Properties of Wood and Perennial Grass Biochars for Possible Composite Application. Bioresources 2016, 11, 1334-1348. [CrossRef]

285. Mrozowski, S. Semiconductivity and Diamagnetism of Polycrystalline Graphite and Condensed Ring Systems. Phys. Rev. 1952, 85, 609-620. [CrossRef]

286. Golden, T.C.; Jenkins, R.G.; Otake, Y.; Scaroni, A.W. Oxygen Complexes on Carbon Surfaces. Proc. Electrochem. Soc. 1983, 84, 61-78.

287. Sánchez-González, J.; Stoeckli, F.; Centeno, T.A. The role of the electric conductivity of carbons in the electrochemical capacitor performance. J. Electroanal. Chem. 2011, 657, 176-180. [CrossRef]

288. Mochidzuki, K.; Soutric, F.; Takokoro, K.; Antal, M.J.; Toth, M.; Zelei, B.; Várhegyi, G. Electrical and Physical Properties of Carbonized Charcoals. Ind. Eng. Chem. Res. 2003, 42, 5140-5151. [CrossRef]

289. Koursaris, A.; See, J.B. The resistivity of mixtures of Mamatwan manganese ore and reducing agents. J.S. Afr. Inst. Min. Metall. 1980, 80, 229-238.

290. Lindstad, T.; Monsen, B.; Osen, K.S. How the ferroalloys industry can meet greenhouse gas regulations. In Proceedings of the INFACON XII, Helsinki, Finland, 6-9 June 2010; pp. 63-70.

291. Bouraoui, Z.; Jeguirim, M.; Guizani, C.; Limousy, L.; Dupint, C.; Gadiou, R. Thermogravimetric study on the influence of structural, textural and chemical properties of biomass chars on $\mathrm{CO}_{2}$ gasification reactivity. Energy 2015, 88, 703-710. [CrossRef]

292. Bui, H.-H.; Wang, L.; Tran, K.-Q.; Skreiberg, O.; Luengnaruemitchai, A. $\mathrm{CO}_{2}$ Gasification of Charcoals in the Context of Metallurgical Application. Energy Procedia 2017, 105, 316-321. [CrossRef]

293. Rollinson, A.N.; Karmakar, M.K. On there activity of various biomass species with $\mathrm{CO}_{2}$ using a standardised methodology for fixed-bed gasification. Chem. Eng. Sci. 2015, 128, 82-91. [CrossRef]

294. Bui, H.-H.; Wang, L.; Tran, K.-Q.; Skreiberg, Ø. $\mathrm{CO}_{2}$ gasificiation of charcoals produced at various pressures. Fuel Process. Technol. 2016, 152, 207-214. [CrossRef]

295. Mani, T.; Mahinpey, N.; Murugan, P. Reaction kinetics and mass transfer studies of biomass char gasification with $\mathrm{CO}_{2}$. Chem. Eng. Sci. 2011, 66, 36-41. [CrossRef]

296. Calo, J.M.; Perkins, M.T. A heterogeneous surface model for the "steady-state" kinetics of the Boudouard reaction. Carbon 1987, 25, 395-407. [CrossRef]

297. Cetin, E.; Moghtaderi, B.; Gupta, R.; Wall, T.F. Biomass gasification kinetics: Influences of pressure and char structure. Compos. Sci. Technol. 2005, 177, 765-791. [CrossRef]

298. Gomez, A.; Silbermann, R.; Mahinpey, N. A comprehensive experimental procedure for $\mathrm{CO}_{2}$ coal gasification: Is there really a maximum reaction rate? Appl. Energy 2014, 124, 73-81. [CrossRef]

299. Gomez, A.; Mahinpey, N. A new model to estimate $\mathrm{CO}_{2}$ coal gasification kinetics based only on parent coal characterization properties. Appl. Energy 2015, 137, 126-133. [CrossRef] 
300. Olsen, S.E.; Ding, W.; Kossyreva, O.A.; Tangstad, M. Equilibrium in production of high carbon ferromanganese. In Proceedings of the INFACON VII, Trondheim, Norway, 11-14 June 1995; pp. 591-600.

301. Kapure, G.; Kari, C.; Rao, S.M.; Raju, K.S. Use of chemical energy in submerged arc furnace to produce ferrochrome: Prospects and limitations. In Proceedings of the INFACON XI, New Delhi, India, 18-21 February 2007; pp. 165-170.

302. Lindstad, T.; Gaal, S.; Hansen, S.; Prytz, S. Improved SINTEF SiO-Reactivity Test. In Proceedings of the INFACON XI, New Delhi, India, 18-21 February 2007; pp. 414-423.

303. Raaness, O.; Kolbeinsen, L.; Byberg, J.A. Statistical Analysis of Properties for Coals Used in the Production of Silicon Rich Alloys. In Proceedings of the INFACON VIII, Beijing, China, 7-10 June 1998; pp. 116-120.

304. Li, F.; Tangstad, M.; Ringdalen, E. Carbothermal Reduction of Quartz and Carbon Pellets at Elevated Temperatures. Metall. Mater. Trans. B 2018, 49, 1078-1088. [CrossRef]

305. Chen, Z.; Ma, W.; Li, S.; Wu, J.; Wei, K.; Yu, Z.; Ding, W. Influence of carbon material on the production of different electric arc furnaces. J. Clean. Prod. 2018, 174, 17-25. [CrossRef]

306. Safarian, J.; Tangstad, M. Slag-carbon reactivity. In Proceedings of the INFACON XII, Helsinki, Finland, 6-9 June 2010; pp. 327-338.

307. Kim, P.P.; Tangstad, M. Kinetic Investigations of SiMn Slags From Different Mn Sources. Metall. Mater. Trans. B 2018, 49, 1185-1196. [CrossRef]

308. Kang, T.W.; Gupta, S.; Saha-Chaudhury, N.; Sahajwalla, V. Wetting and Interfacial Reaction Investigations of Coke/Slag Systems and Associated Liquid Permeability of Blast Furnaces. ISIJ Int. 2005, 45, 1526-1535. [CrossRef]

309. Safarian, J.; Kolbeinsen, L.; Tangstad, M.; Tranell, G. Kinetics and Mechanism of the Simultaneous Carbothermic Reduction of $\mathrm{FeO}$ and $\mathrm{MnO}$ from High-Carbon Ferromanganese Slag. Metall. Mater. Trans. B 2009, 40, 929-939. [CrossRef]

310. Hall, D.O.; Kaale, B.K.; Karekezi, S.; Ravindranath, N.K. Application of Biomass-Energy Technologies; United Nations Centre for Human Settlements (Habitat): Nairobi, Kenya, 1993.

311. Chidumayo, E.N. Woody biomass structure and utilisation for charcoal production in a Zambian Miombo woodland. Bioresour. Technol. 1991, 37, 43-52. [CrossRef]

312. INDEXBOX. Global Wood Charcoal Market Reached \$24B, Buoyed By Robust Demand in Africa. Available online: https: / www.globaltrademag.com/global-wood-charcoal-market-reached-24b-buoyed-by-robus t-demand-in-africa/ (accessed on 18 September 2020).

313. Chudy, R.R.; Hagler, R.W. Dynamics of global roundwood prices-Cointegration analysis. For. Policy Econ. 2020, 115, 1-14. [CrossRef]

314. Dibdiakova, J.; Gjølsjø, S.; Wang, L. Report on Solid Biofuels from Forest-Fuel Specification and Quality Assurance; Report 8/2014; Norwegian Forest and Landscape Institute: Ås, Norway, 2014.

315. Iisa, K.; Robichaud, D.J.; Watson, M.J.; Dam, J.; Dutta, A.; Mukarakate, C.; Kim, S.; Nimlos, M.R.; Baldwin, R. Improving biomass pyrolysis economics by integrating vapor and liquid phase upgrading. Green Chem. 2018, 20, 567-582. [CrossRef]

316. Awasthi, M.K.; Sarsaiya, S.; Patel, A.; Juneja, A.; Singh, R.P.; Yan, B.; Awasthi, S.K.; Jain, A.; Liu, T.; Duan, Y.; et al. Refining biomass residues for sustainable energy and bio-products: An assessment of technology, its importance, and strategic applications in circular bio-economy. Renew. Sustain. Energy Rev. 2020, 127, 109876. [CrossRef]

317. Funke, A.; Niebel, A.; Richter, D.; Abbas, M.M.; Müller, A.-K.; Radloff, S.; Paneru, M.; Maier, J.; Dahmen, N.; Sauer, J. Fast pyrolysis char-Assessment of alternative uses within the bioliq ${ }^{\circledR}$ concept. Bioresour. Technol. 2016, 200, 905-913. [CrossRef]

318. Khundi, F.; Jagger, P.; Shively, G.; Sserunkuuma, D. Income, poverty and charcoal production in Uganda. For. Policy Econ. 2011, 13, 199-205. [CrossRef] 
319. Adanguidi, J.; Padonou, E.A.; Zannou, A.; Houngbo, S.B.E.; Saliou, I.O.; Agbahoungba, S. Fuelwood consumption and supply strategies in mangrove forests-Insights from RAMSAR sites in Benin. For. Policy Econ. 2020, 116, 102192. [CrossRef]

320. Myrhaug, E.H. Non-Fossil Reduction Materials in the Silicon Process-Properties and Behaviour. Ph.D. Thesis, NTNU, Trondheim, Norway, 2003.

Publisher's Note: MDPI stays neutral with regard to jurisdictional claims in published maps and institutional affiliations.

(c) 2020 by the authors. Licensee MDPI, Basel, Switzerland. This article is an open access article distributed under the terms and conditions of the Creative Commons Attribution (CC BY) license (http://creativecommons.org/licenses/by/4.0/). 